\title{
PBPK Modeling as a Tool for Predicting and Understanding Intestinal Metabolism of Uridine 5'-Diphospho-glucuronosyltransferase Substrates
}

\author{
Micaela B. Reddy ${ }^{1, *}$, Michael B. Bolger ${ }^{2}$, Grace Fraczkiewicz ${ }^{2}$, Laurence Del Frari ${ }^{3}$, Laibin Luo ${ }^{4}$, \\ Viera Lukacova ${ }^{2}$, Amitava Mitra ${ }^{5}$, Joyce S. Macwan ${ }^{2}$, Jim M. Mullin ${ }^{2}$, Neil Parrott ${ }^{6}$ and Aki T. Heikkinen ${ }^{7}$ \\ check for \\ updates \\ Citation: Reddy, M.B.; Bolger, M.B.; \\ 1 Early Clinical Development, Department of Clinical Pharmacology Oncology, Pfizer, Boulder, CO 80301, USA \\ 2 Simulations Plus Inc., Lancaster, CA 93534, USA; bolger@simulations-plus.com (M.B.B.); \\ grace@simulations-plus.com (G.F.); viera@simulations-plus.com (V.L.); joyce@simulations-plus.com (J.S.M.); \\ jim@simulations-plus.com (J.M.M.) \\ 3 PKPD Department, Pierre Fabre Laboratories, 31100 Toulouse, France; laurence.del.frari@pierre-fabre.com \\ 4 Material \& Analytical Sciences, Boehringer Ingelheim Pharmaceuticals, Inc., Ridgefield, CT 06877, USA; \\ laibin_2.luo@boehringer-ingelheim.com \\ 5 Clinical Pharmacology and Pharmacometrics, Janssen Research \& Development, \\ Springhouse, PA 19477, USA; amitra24@its.jnj.com \\ 6 Pharmaceutical Sciences, Roche Pharmaceutical Research and Early Development, Roche Innovation Center \\ Basel, F. Hoffmann-La Roche, 4070 Basel, Switzerland; neil_john.parrott@roche.com \\ 7 Admescope Ltd., Fi-90620 Oulu, Finland; aki.heikkinen@admescope.com \\ * Correspondence: micaela.reddy@pfizer.com; Tel.: +1-303-842-4123
} Fraczkiewicz, G.; Del Frari, L.; Luo, L.; Lukacova, V.; Mitra, A.; Macwan, J.S.; Mullin, J.M.; Parrott, N.; et al. PBPK Modeling as a Tool for Predicting and Understanding Intestinal Metabolism of Uridine $5^{\prime}$ Diphospho-glucuronosyltransferase Substrates. Pharmaceutics 2021, 13, 1325. https://doi.org/10.3390/ pharmaceutics13091325

Academic Editor: Jonathan Paul Mochel

Received: 14 July 2021

Accepted: 18 August 2021

Published: 24 August 2021

Publisher's Note: MDPI stays neutral with regard to jurisdictional claims in published maps and institutional affiliations.

Copyright: (c) 2021 by the authors. Licensee MDPI, Basel, Switzerland. This article is an open access article distributed under the terms and conditions of the Creative Commons Attribution (CC BY) license (https:// creativecommons.org/licenses/by/ $4.0 /)$.
Abstract: Uridine 5'-diphospho-glucuronosyltransferases (UGTs) are expressed in the small intestines, but prediction of first-pass extraction from the related metabolism is not well studied. This work assesses physiologically based pharmacokinetic (PBPK) modeling as a tool for predicting intestinal metabolism due to UGTs in the human gastrointestinal tract. Available data for intestinal UGT expression levels and in vitro approaches that can be used to predict intestinal metabolism of UGT substrates are reviewed. Human PBPK models for UGT substrates with varying extents of UGT-mediated intestinal metabolism (lorazepam, oxazepam, naloxone, zidovudine, cabotegravir, raltegravir, and dolutegravir) have demonstrated utility for predicting the extent of intestinal metabolism. Drugdrug interactions (DDIs) of UGT1A1 substrates dolutegravir and raltegravir with UGT1A1 inhibitor atazanavir have been simulated, and the role of intestinal metabolism in these clinical DDIs examined. Utility of an in silico tool for predicting substrate specificity for UGTs is discussed. Improved in vitro tools to study metabolism for UGT compounds, such as coculture models for low clearance compounds and better understanding of optimal conditions for in vitro studies, may provide an opportunity for improved in vitro-in vivo extrapolation (IVIVE) and prospective predictions. PBPK modeling shows promise as a useful tool for predicting intestinal metabolism for UGT substrates.

Keywords: GastroPlus; PBPK; UGT; intestinal metabolism; gut extraction; absorption modeling; oral bioavailability; IVIVE; phase II metabolism

\section{Introduction}

Physiologically based pharmacokinetic (PBPK) modeling has become a valuable tool for understanding drug pharmacokinetic (PK) properties in humans based on nonclinical and in vitro data prior to the first in-human study [1,2]. Additionally, PBPK modeling is an important tool for predicting first-pass loss from intestinal metabolism for cytochrome P450 (CYP) enzymes in humans [3,4] and nonclinical species (e.g., the beagle dog [5]). Extensive literature illustrates the ability to predict the fraction of drug escaping first-pass intestinal metabolism, Fg, for CYP3A substrates (e.g., [4,6,7]). Other enzymes besides CYPs are expressed in the gastrointestinal (GI) tract but are less well studied. Multiple uridine 
5'-diphospho-glucuronosyltransferases, UGTs, are expressed in the GI tract, including UGT1A1, 1A3, 1A4, 1A7, 1A8, 1A10, 2B7, 2B15, and 2B17 [8-11]. This paper builds on the strong foundation of predicting intestinal metabolism for CYP substrates but expands to this less-studied area, the UGTs.

Several first-pass processes can potentially reduce exposure before the drug reaches systemic circulation. PBPK models incorporate system-specific parameters such as enzyme expression levels in the GI tract and liver, as well as compound-specific parameters such as enzyme maximum rate of metabolism, Vmax, and Michaelis constant, $\mathrm{K}_{\mathrm{m}}$, and protein binding data, to predict PK properties such as Fg. Oral administration is subject to firstpass losses from incomplete absorption (i.e., fraction of dose absorbed, $\mathrm{Fa},<1$ ), firstpass intestinal metabolism (i.e., $\mathrm{Fg}<1$ ) and first-pass hepatic metabolism (i.e., fraction moving from the portal vein through the liver-hepatic availability, Fh, $<1)$. The loss of bioavailability, F, due to first-pass processes can be estimated as:

$$
\mathrm{F}=\mathrm{Fa} \times \mathrm{Fg} \times \mathrm{Fh} .
$$

Hepatic metabolism is well-recognized as a main contributor affecting oral bioavailability. However, intestinal metabolism can significantly impact bioavailability, and, in some cases, potentially more than hepatic first-pass metabolism due to less binding in the small intestines (e.g., in PBPK model development for predicting intestinal metabolism for CYP3A4 substrates, setting the unbound fraction in the gut to 1 resulted in more accurate predictions than other assumptions, such as the unbound fraction in plasma, which, in most cases, resulted in a significant underestimation of intestinal metabolism [4]) and differences in expression levels in the intestines compared to the liver [12]. Additionally, the process of transcellular passive absorption exposes all molecules to metabolic enzymes in the intestine, whereas only molecules absorbed into the hepatocyte are exposed to liver enzymes. The complexity of PK processes involved with glucuronidation, e.g., the importance of transporters for glucuronide conjugates as well as enterohepatic cycling involving these glucuronide conjugates and their hydrolysis, has been identified as one reason PBPK modeling has exceptional utility for UGT substrates [13].

PBPK modeling of Fg for UGTs has been limited, possibly due to limited clinical data elucidating Fg for UGT substrates, as well as challenges studying metabolism for these enzymes in vitro [13-15]. There are challenges with in vitro data, with microsomes in particular underestimating clearance [13]. Hepatocytes, both in short-term suspension (fresh and cryopreserved) and in a long-term co-cultured assay, may be useful in vitro tools for in vitro-in vivo extrapolation, IVIVE [16,17]. However, even hepatocytes may underestimate clearance for UGT substrates [18]. UGT in vitro assay conditions often impact results [14,19], and recent work has aimed at optimizing conditions (more details in Section 4). Even reaction phenotyping for UGTs can be challenging [19]. Intestinal microsomes have been demonstrated to be a potentially useful tool for predicting UGT intestinal metabolism [20], but this assay is challenging, particularly for more metabolically stable compounds. Challenges for UGT IVIVE also include organ-dependent specificity as well as clinical relevance for polymorphisms [21,22]. Nonetheless, recent work has demonstrated the potential utility of PBPK modeling to predict UGT-mediated intestinal metabolism through an IVIVE approach $[16,23]$ and a focus on clinical absorption, distribution, metabolism and excretion (ADME) and PK data [24].

In this review, scientists from multiple companies participating in the GastroPlus ${ }^{\circledR}$ User Group Steering Committee review examples of PBPK models for UGT substrates with a focus on Fg predictions. The incorporation of intestinal metabolism in PBPK models is described. The data available to parameterize the UGT levels in the GI tract are reviewed along with in vitro data useful for studying UGT metabolism to aid in model parameterization. Additionally, PBPK-DDI predictions for UGT1A1 substrates raltegravir and dolutegravir with UGT1A1 inhibitor atazanavir are included in these examples to illustrate the role of intestinal metabolism for DDIs. Although GastroPlus was used for all the examples, the approaches and information are generally applicable to PBPK modeling 
for predicting Fg for UGT substrates. Along with these industry examples, limitations of the approach are described. Other examples of UGT-mediated intestinal metabolism impacting exposures in the clinic are presented. Finally, the potential utility of an in silico tool for predicting substrate specificity for various UGTs is discussed in the context of its utility for application to PBPK modeling for prediction of first-pass loss from intestinal metabolism and bioavailability.

\section{Incorporating Intestinal Metabolism in PBPK Models}

The following section describes the GastroPlus PBPK model because it was used in the examples in Section 5. Other PBPK modeling tools, e.g., Simcyp ${ }^{\circledR}$ [25] and PK$\mathrm{Sim}^{\circledR}[26]$, include similar physiological processes, although there are some differences in how different aspects of physiology are incorporated in the model.

UGTs are among the most important Phase II metabolic enzymes. They conjugate glucuronic acid with hydroxy groups, carboxylates, amines, heterocyclic nitrogens, and other nucleophilic centers in xenobiotics. Such polar groups generally reduce passive intestinal absorption. Often, drug candidates are designed to have high passive permeability by avoiding highly polar functional groups, and glucuronidation occurs at sites that are often introduced by phase I oxidation-hence the term "Phase II." However, for some drugs, direct glucuronidation is the primary mechanism of elimination. PBPK modeling is a potentially useful tool for understanding the ADME of such compounds.

The advanced compartmental absorption and transit (ACAT) model describes the local solubility, dissolution, precipitation, absorption, metabolism, and active transport in each region of the intestinal tract for drugs administered orally. A compound must dissolve before it is available for absorption. Drug dissolution in individual intestinal compartments is calculated in ACAT by taking into account the amount and the composition ( $\mathrm{pH}$ and bile salt concentration) of fluid in each intestinal compartment, the compartment-specific solubility and diffusion coefficient of a compound, and the formulation properties (e.g., size, shape, and density of the dissolving API particles, or the release rate from a modified release formulation). The dissolved compound can undergo precipitation and/or degradation inside the gut, which can lower the amount of compound available for absorption, and these processes can be parameterized based on in vitro experiments.

The absorption model includes passive transcellular and paracellular diffusion and carrier-mediated transport. The first-order absorption rate coefficients (units of $s^{-1}$ ) in individual intestinal compartments are calculated from the product of effective permeability (units of $\mathrm{cm} / \mathrm{s}$ ) and absorption scale factors (units of $\mathrm{cm}^{-1}$ ), which account for changes in the drug's ionization and absorptive surface area in the different parts of the small intestine and colon $[27,28]$. The carrier-mediated transport processes are described via transporter kinetics (Vmax, $\mathrm{K}_{\mathrm{m}}$ values) and local gut transporter expressions. Intestinal transporters can decrease (efflux) or increase (influx) the amount of compound entering the enterocyte from its passive transcellular apical absorption. Similar processes exist on the basolateral membrane for passive or transporter-mediated movement into the portal vein.

Once a compound gets absorbed into intestinal enterocytes, it may be subject to gut metabolism. This first-pass process can lower the amount of drug entering the portal vein and then liver, impacting bioavailability.

The ACAT model describes intestinal first-pass metabolism due to UGT enzymes using Michaelis-Menten kinetics with $\mathrm{K}_{\mathrm{m}}$ and Vmax values typically determined from in vitro experiments and converted to in vivo values. Then, built-in expression levels of specific UGT enzymes in different intestinal compartments are used in conjunction with the provided $\mathrm{K}_{\mathrm{m}}$ and Vmax parameters to determine the extent of compound extraction in these gut regions and the potential for saturation with increasing dose levels. The region-specific intestinal expression levels of UGT enzymes in the ACAT model are defined as fractions of the total expression level of each enzyme in the entire liver if the enzyme is expressed in gut and liver, or as a relative expression in gut compartments if only the gut is involved. 
The human ACAT and PBPK model has built-in expression levels of UGTs that are tissue-specific. For example, some UGTs that are expressed in the liver are not expressed in the gut, e.g., UGT1A7, UGT1A8, and UGT1A10 [29]. Additionally, some UGTs that are expressed in the liver and gut may not be significantly expressed in the kidneys (e.g., UGT1A1 [30]). Therefore, simulations with an appropriately parameterized model may clarify the organs involved with metabolizing a drug.

The interplay between processes taking place in the gut and their dependence on compound properties creates a complex picture of drug absorption. The standard output in GastroPlus includes the fraction of dose dissolved, Fa, FDp (i.e., fraction of dose passing into the portal vein, $=\mathrm{Fa} \times \mathrm{Fg}$ ), F, area under the plasma concentration-time curve (AUC), maximum observed total plasma concentration (Cmax), and $\mathrm{Cp}$-time profile, but many other simulation results, e.g., metabolite produced by a specific enzyme in a specific organ, can easily be incorporated. Given the potential complexity with additional mechanisms impacting systemic PK, PBPK modeling may be a useful tool for an integrated understanding of properties impacting bioavailability and PK in the hands of an experienced modeler.

\section{UGT Expression in the GI Tract}

The intestinal, hepatic, and renal UGT expression levels available in the current human ACAT model and human physiology in GastroPlus are based on a combination of protein and mRNA level information collected from four publications $[9,10,31,32]$. The metabolic enzyme abundance in the segments of the ACAT model is expressed relative to the total hepatic abundance in a typical adult subject based on relative intestine and liver weights and microsomal protein yields, as summarized by Soars et al. [33]. In the case that an enzyme is not present in the liver, the intestinal abundance is represented relative to the whole small intestine instead. A homogenous UGT enzyme abundance per intestinal surface area in the small intestines is assumed.

Experimental data on the variation of UGT protein abundance along the intestine are limited and partially inconsistent. Drozdzik and coworkers [34] found that measurements of UGT protein levels in tissue homogenates suggested a tendency towards higher UGT1A1, UGT1A3, and UGT2B7 concentration in mucosal tissue from jejunum than from duodenum or ileum. In contrast, Zhang and coworkers [35] reported relative UGT1A1, UGT1A3, UGT1A10, UGT2B7, and UGT2B17 protein abundance data suggesting a tendency towards highest UGT abundance in the duodenum and decreasing levels towards the more distal parts of the small intestine. However, this result was obtained when normalizing to the protein abundance of enterocyte marker proteins sucrase isomaltase and villin-1 in cryopreserved human intestinal mucosa samples, whereas without normalization to enterocyte markers, the same absolute UGT enzyme protein abundance data did not show clear differences in UGT abundance between the small intestine segments. Similarly, the results reported by Couto et al. [36] did not show statistically significant differences in UGT1A1, UGT1A3, UGT1A6, and UGT2B7 protein abundance between different segments of the small intestine. Consequently, the UGT abundance profiles in the human ACAT model, built in GastroPlus version 9.8, can be considered to be reasonably well supported by these experimental data.

When used in the context of PBPK models for the prediction of drug metabolism in tissues, both mRNA expression and protein abundance levels serve as surrogates for enzyme activity. However, for prediction of drug metabolism, protein abundance is generally preferred over mRNA expression [36] since it is more closely linked to enzyme activity. Post-translational regulation and the dynamic nature of protein expression in high turnover tissues such as the gut wall may mean that mRNA expression and protein abundance levels do not correlate well. Consequently, a significant body of liquid-chromatographymass-spectrometry-based UGT protein abundance data in human tissues has emerged in the literature during recent years [8,11,34-38]. Based on the mean intestinal protein levels reported in the literature, as reviewed in $[39,40]$, the distribution of UGTs in the intestine is UGT2B17, 52.2\% > UGT1A1, 14.6\% > UGT2B7, 9.2\% > UGT1A10, 7\% = UGT1A8 7\%. How- 
ever, there are considerable study-to-study differences in the reported quantitative UGT protein abundance in the gut wall. Differences in experimental practices on applying quantitative liquid chromatography-mass spectrometry proteomic techniques and consequent variability in reported abundances of the same proteins has been acknowledged [41] and efforts towards harmonized guidelines for LC-MS proteomic experimental practices and data analysis have been made [42]. Although part of the variability in reported absolute protein abundance data may be attributed to true interindividual variability between donors, the currently existing data on absolute UGT abundance in the human intestine are likely to be associated with considerable technical variability and quantitative uncertainty. Consequently, combining absolute protein abundance data from various studies may result in biased estimates of mean abundance and skew the estimation of interindividual variability.

In addition to abundance of enzyme protein in samples obtained via liquid chromatography-mass spectrometry (LC-MS) quantification, suitable scaling factors are required to estimate the total enzyme abundance in the whole tissue. The weight of the small intestine mucosal tissue (120 g) has been estimated to equate to approximately $8 \%$ of total liver tissue weight (1500 g) [43]. Correspondingly, the total amount of microsomal protein in the small intestine has been estimated to correspond to approximately 4 to $10 \%$ of total hepatic microsomal protein in the human liver $[33,43]$. The levels of UGT abundance in the small intestine relative to that in the liver were calculated assuming results on protein abundance and RNA levels in the liver and intestine are subject to a similar (albeit potentially unknown) level of quantitative bias when a similar methodology is used for samples from both tissues (Table 1). Comparison of the intestine-to-liver ratios based on several literature sources suggests that intestinal level estimates for UGT1A1 are reasonably consistent between several sources of experimental data, and the description in the ACAT model has a strong foundation. However, more limited and less consistent information is available for the other UGT enzymes. Potentially lower intestinal levels of UGT1A4, UGT1A6, UGT1A9, UGT2B7, and UGT2B17 than in the current ACAT model could be justified based on the existing protein abundance data on these enzymes. UGT expression profiles in the large intestine described in the current ACAT model are based on mRNA levels [10]. Data on UGT protein expression in the colon are limited. The majority of publications reporting LC-MS data on intestinal UGT protein levels have focused on the small intestines and those addressing UGT levels also in the colon [34] have reported levels below the limit of quantification. As more is learned about the expression and activity of the various UGTs in the GI tract, the parameters may be updated to match the state of the science. 
Table 1. Intestinal and hepatic UGT protein abundance and mRNA expression ${ }^{1}$.

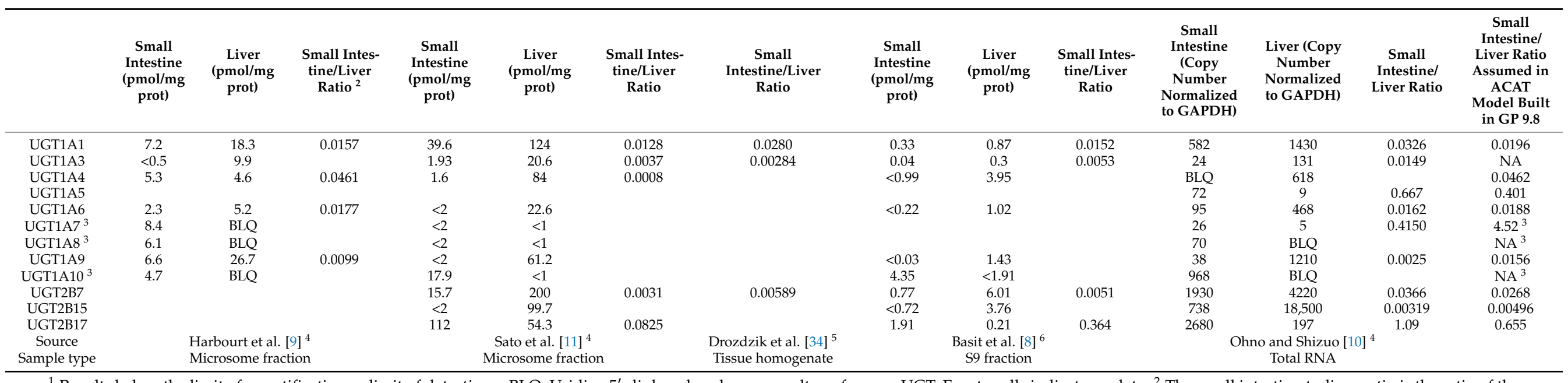

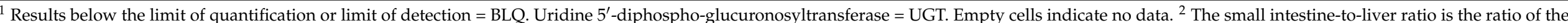

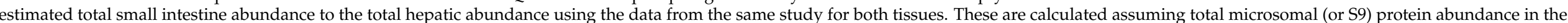

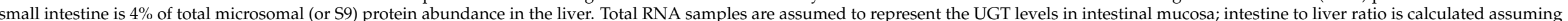

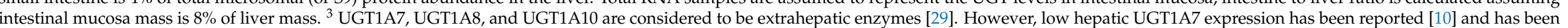

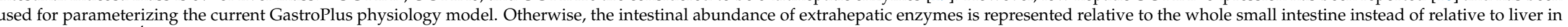

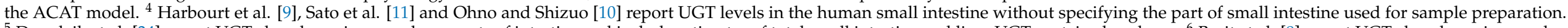

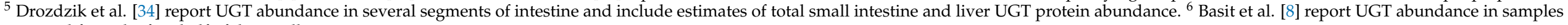
prepared from the first half of the small intestine. 


\section{In Vitro Methods to Measure UGT-Mediated Drug Metabolism}

In vitro data on hepatic drug metabolism are generally required in drug development, whereas dedicated in vitro data on intestinal metabolism are likely to be generated on an ad hoc basis. Therefore, a reasonable approach to predict intestinal metabolism and to parameterize intestinal metabolism in PBPK models is to leverage in vitro methods established for prediction of hepatic metabolism and combine this information with reaction phenotyping data and information on the relative abundance of metabolic enzymes in the liver and intestine [2].

Several well-established in vitro methods are available for studying hepatic metabolism. Subcellular fractions such as microsomes may be used for studying metabolism by enzymes present and active in the given fraction, whereas primary human hepatocytes, either in suspension or as coculture models, represent holistic models for the metabolic machinery of the liver [44-46]. UGTs may be studied using microsomes fortified with uridine $5^{\prime}$-diphosphoglucuronic acid (UDPGA). However, clearance of UGT substrates in vitro using microsomes or other subcellular fractions has generally been associated with underprediction of hepatic clearance in vivo, and these underpredictions may be attributed to several mechanisms $[13,18]$. To overcome tendency towards underprediction, several details in microsomal incubation conditions have been explored and optimized, including preincubation of microsomes with pore forming agent alameticin to improve the access of UDPGA to the enzymes, supplementing incubations with albumin to bind UGT inhibiting free fatty acids, and optimization of incubation buffer constituents $[19,47-49]$. The activity of different UGT enzymes is not always similarly affected by variables of incubation conditions, and thus standardization of incubation conditions is needed and has been suggested [50]. However, the suggested experimental conditions may not be generally accepted, and thus uncertainty remains as to whether the contribution of individual UGT enzymes to microsomal clearance quantitatively resembles the relative contributions of these enzymes in vivo.

Due to potential limitations in the data generated with hepatic cellular fractions, intact primary human hepatocytes may be considered a gold standard for predicting hepatic clearance. Clearance measured in vitro with cryopreserved primary hepatocytes in suspension seems to be associated with a similar tendency towards clearance underprediction independent of whether the compounds are primarily eliminated via CYP or UGT enzymes [51]. This similar tendency suggests that the prediction of hepatic UGT-mediated clearance may not be associated with higher uncertainty than the prediction of CYP-mediated clearance. Cryopreserved primary hepatocytes in suspension are suitable for relatively short incubations and thus have limited utility for low-clearance compounds. Therefore, coculture models, such as $\mathrm{H}_{\mu \mathrm{rel}}{ }^{\circledR}$ and HepatoPac ${ }^{\circledR}$, including primary human hepatocytes cocultured with supporting cell types to allow longer-term incubations with consistent metabolic activity and hepatocyte viability throughout incubation, have been established. Evaluation of these coculture models have focused initially on compounds metabolized primarily via CYP enzymes [45,52,53], but promising quantitative prediction performance has also been demonstrated with compounds metabolized primarily by UGTs [16].

In addition to total metabolic clearance, utilization of data on hepatic metabolism for prediction of intestinal metabolism requires reliable reaction phenotyping data to specify the contribution of individual enzymes on hepatic metabolism and information on relative enzyme abundance in the liver and intestine. UGT protein levels in the intestine, relative to those in the liver, are discussed in Section 3. Use of enzyme-specific chemical inhibitors in incubations with an in vitro model for hepatic metabolism is accepted as one of the standard methods for cytochrome P450 reaction phenotyping, whereas a similar approach for UGT phenotyping is partially limited by a lack of generally accepted selective chemical inhibitors [19]. Another standard method for estimating contributions of individual UGTs on metabolism is to use recombinant UGT enzymes. The advantages of recombinant enzyme assays include certainty of the assay enzyme specificity and capability of addressing extrahepatic enzymes, such as UGT1A7, UGT1A8, and UGT1A10. However, using recom- 
binant enzyme data to predict metabolism requires adequate IVIVE, taking into account the active enzyme content in vitro and in vivo, and also correction for potential differences in intrinsic enzyme activities between in vitro incubations and tissues in vivo. Intersystem extrapolation factor (ISEF) and relative activity factor (RAF) approaches have been utilized for this purpose with CYP enzymes [54-56] and a logical approach is to establish similar scaling factors for UGTs. Recent advances to establish RAF for UGTs have been made [57], but extrapolation of enzyme activity from recombinant enzymes to the in vivo situation is likely to be associated with higher uncertainty for UGTs and other phase II enzymes than for CYP enzymes. Furthermore, work to establish and evaluate RAFs for UGTs has been limited to hepatic UGTs; thus, IVIVE from recombinant enzyme data for extrahepatic UGTs requires further investigation.

The prediction of intestinal metabolism by scaling from hepatic clearance is bound to omit the contribution of enzymes present in the gut wall but not in the liver. Thus, the prediction of the intestinal metabolism of compounds eliminated via extrahepatic enzymes may benefit from in vitro methods specifically addressing intestinal metabolism. In vitro methods to study intestinal metabolism are often associated with high variability [58]; additionally, the relatively low metabolic activity in intestinal in vitro models may limit the utility of these methods to compounds with relatively fast metabolic turnover. Some promising examples of predicting intestinal UGT metabolism based on intestinal microsome data have been published [20]. However, use of intestinal microsomes for UGT metabolism may be expected to have similar limitations to the use of liver microsomes for the prediction of hepatic metabolism of UGT substrates. Consequently, recently published work on intestinal cryopreserved primary human enterocytes and cryopreserved human intestinal mucosal epithelium provides interesting and theoretically holistic in vitro models for intestinal metabolism, including both CYP and non CYP enzymes [35,59-61]. However, information on quantitative prediction performance of these novel intestinal metabolism in vitro models is currently still limited.

\section{PBPK Modeling of UGT Intestinal Metabolism}

The following case studies review PBPK models for UGT substrates with consideration of intestinal metabolism (Table 2). All the examples were done in GastroPlus.

\subsection{Lorazepam (UGT2B7, UGT2B15), Oxazepam (UGT1A9, UGT2B15), Naloxone (UGT2B7), and Zidovudine (UGT2B7, CYP3A4)}

Recently, Docci et al. [23] provided a detailed description of PBPK model construction for four UGT substrates: benzodiazepines lorazepam (UGT2B7, UGT2B15) and oxazepam (UGT1A9, UGT2B15), the antiretroviral zidovudine (UGT2B7, CYP3A4), and the opioid antagonist naloxone (UGT2B7). Docci followed a systematic model building approach, leveraging intrinsic clearance measurements made with HepatoPac ${ }^{\circledR}$ [62], which is a micropatterned coculture of primary human hepatocytes with mouse fibroblasts. Improved IVIVE performance for hepatic UGT substrates had been demonstrated in a companion paper from the same authors [16]. Docci et al. combined the intrinsic hepatic clearance estimates from Hepatopac with additional in vitro phenotyping data and published clinical mass balance studies to build PBPK models with the total systemic glucuronidation clearance apportioned to specific UGT isoforms expressed in liver and kidney. The estimation of relative contribution to systemic clearance of liver and kidney thus relied on the physiological model framework and the UGT isoform expression levels included as defaults in GastroPlus V9.7. After verification of systemic clearance simulations using clinical studies performed with intravenous dosing, the models were applied to simulate oral pharmacokinetics. Intestinal metabolism was estimated assuming an unbound fraction in the enterocyte of $100 \%$ and default intestinal UGT isoform regional expression ratios. These ratios scale the Vmax values for each UGT isoform in each gut compartment relative to the amount of that isoform in a typical human liver. 
Table 2. Summary of example UGT substrate PBPK models including key compound properties ${ }^{1}$.

\begin{tabular}{|c|c|c|c|c|c|c|c|}
\hline Parameter & Cabotegravir & Dolutegravir & Lorazepam & Oxazepam & Naloxone & Raltegravir & Zidovudine \\
\hline Drug class & Antiretroviral & Antiretroviral & Benzodiazepine & Benzodiazepine & Opioid antagonist & Antiretroviral & Antiretroviral \\
\hline Model reference & Internal Sim+ & {$[24]$} & [23] & [23] & [23] & [24] & [23] \\
\hline $\mathrm{pKa}$ & 4.52 (acid) & 4.58 (Acid), 8.2 (Acid) & $\begin{array}{c}1.3 \text { (base) } \\
11.5 \text { (acid) }\end{array}$ & $\begin{array}{l}2.57 \text { (base) } \\
11.31 \text { (acid) }\end{array}$ & 7.9 (base) & 5.5 (acid), 1.53 (base) & 9.1 (acid) \\
\hline $\log P$ & $2.16^{2}$ & 2.16 & 2.4 & 2.4 & 1.92 & 0.58 & 0.06 \\
\hline $\begin{array}{l}\text { Permeability } \\
\left(\mathrm{cm} / \mathrm{s} \times 10^{4}\right)\end{array}$ & 2.54 & 2.37 & 3.3 & 3.6 & 4 & 1.79 & 1.9 \\
\hline$f u, p$ & 0.01 & 0.009 & 0.11 & 0.6 & 0.56 & 0.17 & 0.74 \\
\hline $\mathrm{Rbp}$ & 0.58 & 0.55 & 0.75 & 1.1 & 1.1 & 0.60 & 0.86 \\
\hline Major CL mechanism & $\begin{array}{l}\text { Metabolism }(\sim 79 \%) \\
\quad \text { renal }(\sim 21 \%)\end{array}$ & Metabolism & Metabolism & Metabolism & Metabolism & $\begin{array}{l}\text { Hepatic }(88-95.6 \%) \\
\text { renal }(4.4-12 \%)\end{array}$ & $\begin{array}{l}\text { Metabolism }(\sim 75 \%) \\
\text { renal }(\sim 25 \%)\end{array}$ \\
\hline $\begin{array}{l}\text { Hepatic enzymes, } \mathrm{f}_{\mathrm{m}} \\
\text { in } \%\end{array}$ & $\begin{array}{l}\text { UGT1A1 (66.8\%), } \\
\text { UGT1A9 }(33.2 \%)\end{array}$ & $\begin{array}{l}\text { UGT1A1 (51\%), } \\
\text { CYP3A4 (21\%) }\end{array}$ & $\begin{array}{l}\text { UGT2B7 (42\%), } \\
\text { UGT2B15 (58\%) }\end{array}$ & $\begin{array}{l}\text { UGT1A9 (13\%), } \\
\text { UGT2B15 (87\%) }\end{array}$ & UGT2B7 (100\%) & UGT1A1 (100) & $\begin{array}{l}\text { UGT2B7 (85\%), } \\
\text { CYP3A4 (15\%) }\end{array}$ \\
\hline Simulated Fg & $85.1 \%$ & $\begin{array}{c}68-84 \% \text { (dose } \\
\text { dependent) }\end{array}$ & $95 \%^{3}$ & $96 \%{ }^{3}$ & $17 \%$ & $51-52 \%$ & $93 \%^{3}$ \\
\hline Simulated Fh & $99.82 \%$ & $99 \%$ & $96 \%$ & $94 \%$ & $6 \%$ & $79 \%$ & $53 \%$ \\
\hline
\end{tabular}

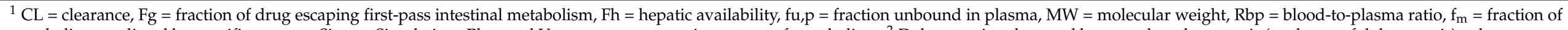

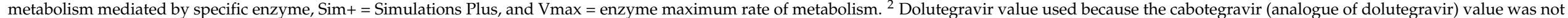

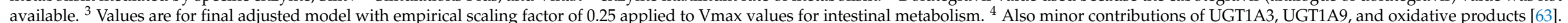


Results for the default simulations of oral pharmacokinetics were interesting, as a consistent underprediction of bioavailability was apparent for three of the four substrates, namely lorazepam, oxazepam, and zidovudine. For lorazepam, $81 \%$ was predicted with 93\% observed; for oxazepam, $79 \%$ was predicted compared to $92 \%$ observed; and for zidovudine, $40 \%$ was predicted compared to $63 \%$ observed. Parameter sensitivity analyses revealed that variations in the enzyme activity in the gut (Gut Vmax) caused a relatively high change in the simulated Fg for these three models, while other tested parameters (permeability, solubility, fu in enterocytes) were less sensitive $(<10 \%$ change). Hence, when the models were adjusted by applying a consistent scaling factor of 0.25 -fold to the Gut Vmax values for the involved UGT isoforms (UGT2B15, UGT2B7, and UGT1A9), the simulated intestinal metabolism was reduced, and bioavailability estimates and oral profiles agreed better with the observed data. For naloxone, a similar approach was not fruitful since, in contrast to the other three drugs, naloxone has low bioavailability due to a high hepatic extraction ratio, making it more sensitive to hepatic metabolism changes than to intestinal metabolism.

\subsection{Cabotegravir (UGT1A1, UGT1A9)}

Cabotegravir is a potent integrase inhibitor, particularly useful against many subtypes of human immunodeficiency virus 1 (HIV-1) and is an analogue of dolutegravir. Cabotegravir is a moderately lipophilic low solubility compound in its neutral form with $<10 \mathrm{ug} / \mathrm{mL}$ solubility [64]. However, with a pKa of 4.52 (acid), it is almost completely ionized in the small intestine, and the solubility at $\mathrm{pH} 6.5$ is $0.83 \mathrm{mg} / \mathrm{mL}$ based on a combination of in silico and in vitro measurements. Cabotegravir has essentially no dissolution or precipitation limitations at its clinical dose of $30 \mathrm{mg}$ when administered as a solution, as was done in the studies used for model development. Additionally, cabotegravir has a predicted human effective jejunal permeability of $2.54 \times 10^{-4} \mathrm{~cm} / \mathrm{s}$, which puts it the high permeability category. Because there are no dissolution (due to solution formulation), precipitation, or absorption limitations, cabotegravir is an excellent candidate to analyze UGT metabolism in the absence of any external complicating factors. The primary route of metabolism of cabotegravir is via glucuronidation by UGT1A1 and UGT1A9 [64].

PBPK simulations were conducted in GastroPlus ${ }^{\circledR} 9.6$ (Simulations Plus, Inc, Lancaster, CA) and ADMET Predictor ${ }^{\circledR} 8.1$ (Simulations Plus, Inc., Lancaster, CA, USA) was used to estimate most physicochemical inputs. Additional inputs were either experimentally determined values or substituted values from analog compound dolutegravir, which is only one carbon atom different from cabotegravir. Table 2 summarizes the key inputs for the cabotegravir model. The Lukacova model was used to calculate all tissue partition coefficients and passive kidney filtration was employed based on fraction unbound in plasma (fu,p) and glomerular filtration rate (GFR). The fu,p and blood-to-plasma ratio (Rbp) were estimated from whole blood and plasma radioactivity experimental data in the literature [64]. UGT1A1 and UGT1A9 gut and liver metabolism was described using in vitro values [64]. The in vitro $\mathrm{K}_{\mathrm{m}} / \mathrm{Vmax}$ values were converted to in vivo values for gut and liver using the built-in IVIVE conversion tool that utilizes all default expression levels. Human liver microsomes (HLMs) with recombinant UGT1A1 and 1A9 enzymes at a concentration of $0.5 \mathrm{mg} / \mathrm{mL}$ were used to estimate drug metabolism using the Halifax method for in vitro binding. $\mathrm{K}_{\mathrm{m}}$ and Vmax values for in vitro metabolism of UGT1A1 and $1 \mathrm{~A} 9$ were 148 and $90 \mathrm{uM}$ and 660 and $200 \mathrm{pmol} / \mathrm{min} / \mathrm{mg}$ protein, respectively [64]. Default gut and liver UGT expression levels were used as described in Section 3.

A combinatorial approach utilizing in vitro and in silico data was then utilized to predict the in vivo concentration versus time profile of two oral solution formulations, as shown in Figure 1. Study 1 is a $28.2 \mathrm{mg}$ oral solution administered to six male subjects with an average age of $41.2 \mathrm{yr}$ and weight of $88.8 \mathrm{~kg}$ [64]. The observed versus predicted Cmax $(2.6$ and $2.38 \mathrm{ug} / \mathrm{mL})$ and AUC (0-240 h) $(99.4$ and $109.1 \mathrm{ug} \cdot \mathrm{h} / \mathrm{mL})$ are within $10 \%$ error, a reasonable result when considering the IVIVE extrapolation of metabolism. Study 2 is a $30 \mathrm{mg}$ oral solution dosed in both male and female subjects, and an average 
weight of $79.63 \mathrm{~kg}$ was used to generate the PBPK physiology [65]. The observed and predicted Cmax (3.2 and $2.8 \mathrm{ug} / \mathrm{mL})$ and AUC $(0-168 \mathrm{~h})(119.2 \mathrm{and} 148.3 \mathrm{ug} \cdot \mathrm{h} / \mathrm{mL})$ are within $20 \%$ error in this case. In both cases, almost all first-pass extractions are attributable to gut first-pass extractions at 15.4 and $14.3 \%$. Hepatic first pass extraction is very low and approximately $0.18 \%$ in both cases. This modeling result is from the high unbound enterocyte concentrations relative to the low unbound liver concentrations due to the low fraction unbound in plasma.

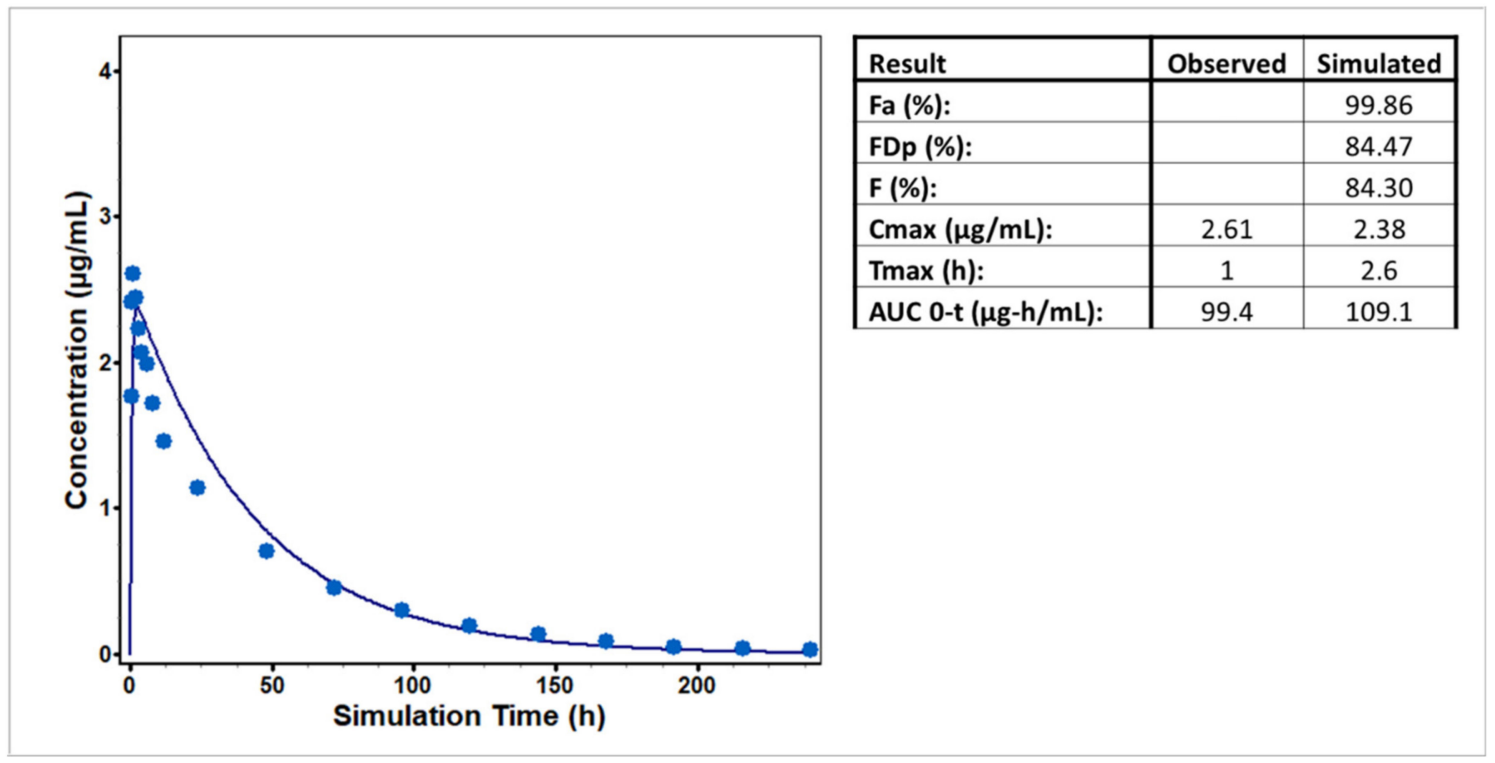

(A)

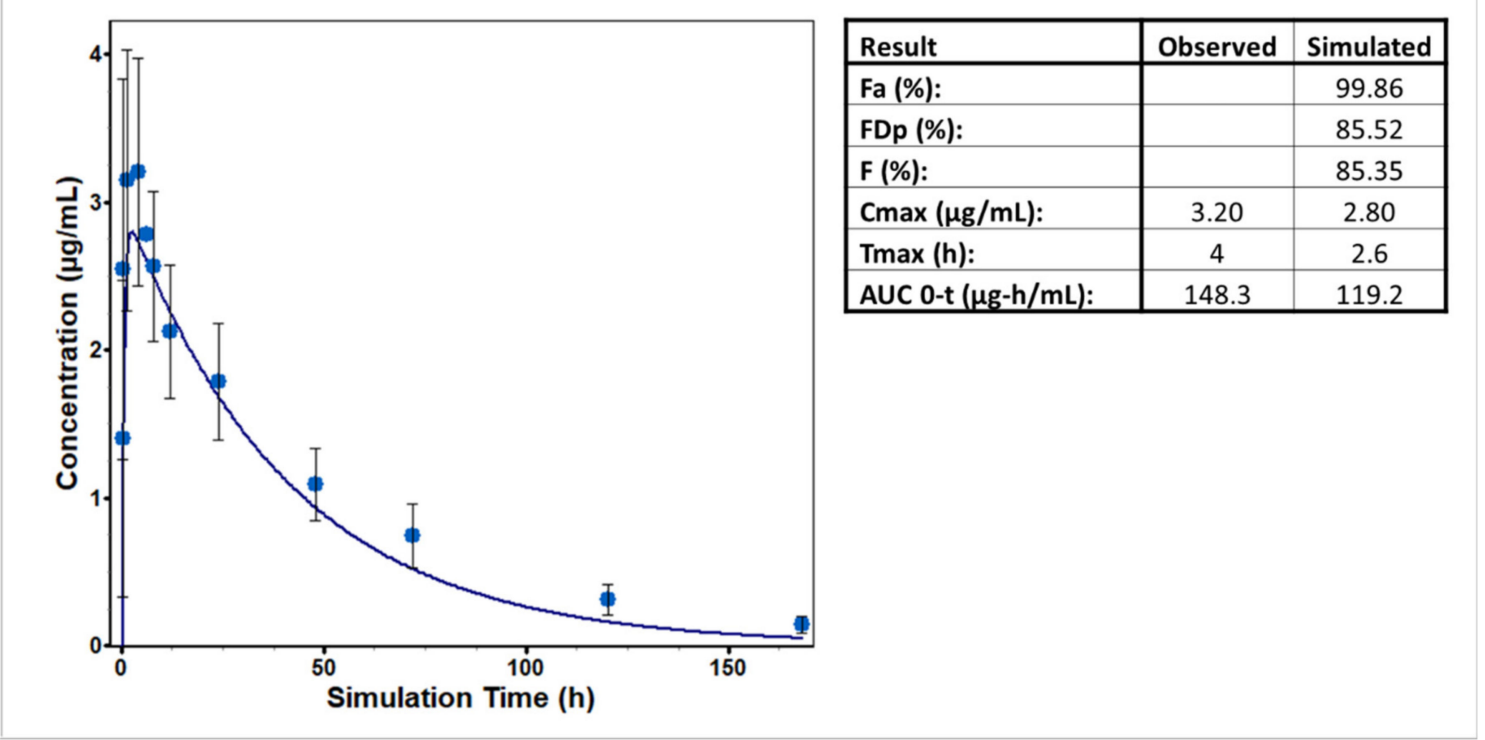

(B)

Figure 1. PBPK Model prediction of (A) $28.2 \mathrm{mg}$ and (B) $30 \mathrm{mg}$ oral solution of cabotegravir. Dark blue curves and light blue points represent predicted versus observed plasma concentration. The tables list: fraction of dose absorbed (Fa), fraction of dose reaching the portal vein (FDp), bioavailability (F), maximum observed total plasma concentration (Cmax), time at which the Cmax was observed (Tmax), and the area under the plasma concentration-time curve from time zero to $t$ $\left(\mathrm{AUC}_{0-\mathrm{t}}\right)$.

Limitations of the current modeling approach include lack of an intravenous, IV, PK study in humans, measured permeability data, and experimentally determined LogP or $\log \mathrm{D}$ vs. $\mathrm{pH}$ profile. Of these limitations, the IV data is key. While the in vitro data for 
metabolism and the PBPK approach, in this case, provided accurate $\mathrm{Cp}$-time predictions, the overall first-pass effect cannot be assessed with full certainty without PK data from IV administration.

\subsection{Dolutegravir (UGT1A1, CYP3A4)}

Dolutegravir, a HIV-1 integrase inhibitor, is a Biopharmaceutics Drug Disposition Classification System class two drug. It is a substrate for the P-glycoprotein (P-gp) and breast cancer resistance protein (BCRP) transporters but exhibits rapid oral absorption and dose-proportional kinetics. These properties suggest that dolutegravir absorption is mainly governed by its high intrinsic intestinal permeability with no major impact of P-gp and BCRP. Dolutegravir metabolism was determined in vitro to be mainly metabolized by UGT1A1 (fraction of metabolism mediated by UGT1A1, $\mathrm{f}_{\mathrm{m}, \mathrm{UGT1A} 1}=0.51$ ) and cytochrome P450 3A4 $\left(f_{\mathrm{m}, \mathrm{CYP} 3 \mathrm{~A} 4}=0.21\right)$. UGT1A3 and UGT1A9 are only minor pathways $\left(\mathrm{f}_{\mathrm{m}, \mathrm{UGT1A} 3}=0.028\right.$ and $\left.\mathrm{f}_{\mathrm{m}, \mathrm{UGT1A}}=0.055\right)$ [63]. Less than $1 \%$ of unchanged drug is excreted urine [66].

The dolutegravir PBPK model was developed and validated in GastroPlus ${ }^{\mathrm{TM}}$ v9.0. In the model, the dolutegravir metabolic clearance was assumed to be mediated by the UGT1A1 and CYP3A4 enzymes only, and since P-gp and BCRP impact was expected to be negligible, they were not included in the model.

Dolutegravir $\mathrm{K}_{\mathrm{m}}$ and Vmax values for UGT1A1 were available from in vitro measurements in HLMs and recombinant human UGT1A1 (rUGT1A1) [63]. The $\mathrm{K}_{\mathrm{m}}$ and Vmax values measured in HLMs were approximately six- to seven-fold higher than values measured in $\mathrm{rCYP}$, but very similar intrinsic clearances were measured in the two systems $(2.7 \mu \mathrm{L} / \mathrm{min} / \mathrm{mg}$ and $3.2 \mu \mathrm{L} / \mathrm{min} / \mathrm{mg}$ measured in HLMs and rUGT1A1, respectively). The in vitro $\mathrm{K}_{\mathrm{m}}$ and Vmax were used in the initial model parameterization along with built-in expression levels of both enzymes in gut, liver, and kidney. The data from both in vitro systems underpredicted the in vivo clearance (Figure 2). The single dose $\mathrm{Cmax}$ values were predicted with reasonable accuracy (average prediction error 13\%). However, the average prediction errors for steady-state $\mathrm{Cmax}$ as well as single dose and steady-state AUCs were more significant (two- to three-fold overprediction). Therefore, the model was further refined by fitting some of the parameters against clinical data after 25, 50, and $100 \mathrm{mg}$ single dose administration in fasted subjects [67] and a crossover study with $50 \mathrm{mg}$ single dose administration in fasted and fed (moderate-fat meal) subjects [68] and by utilizing information from mass balance and DDI studies [69].
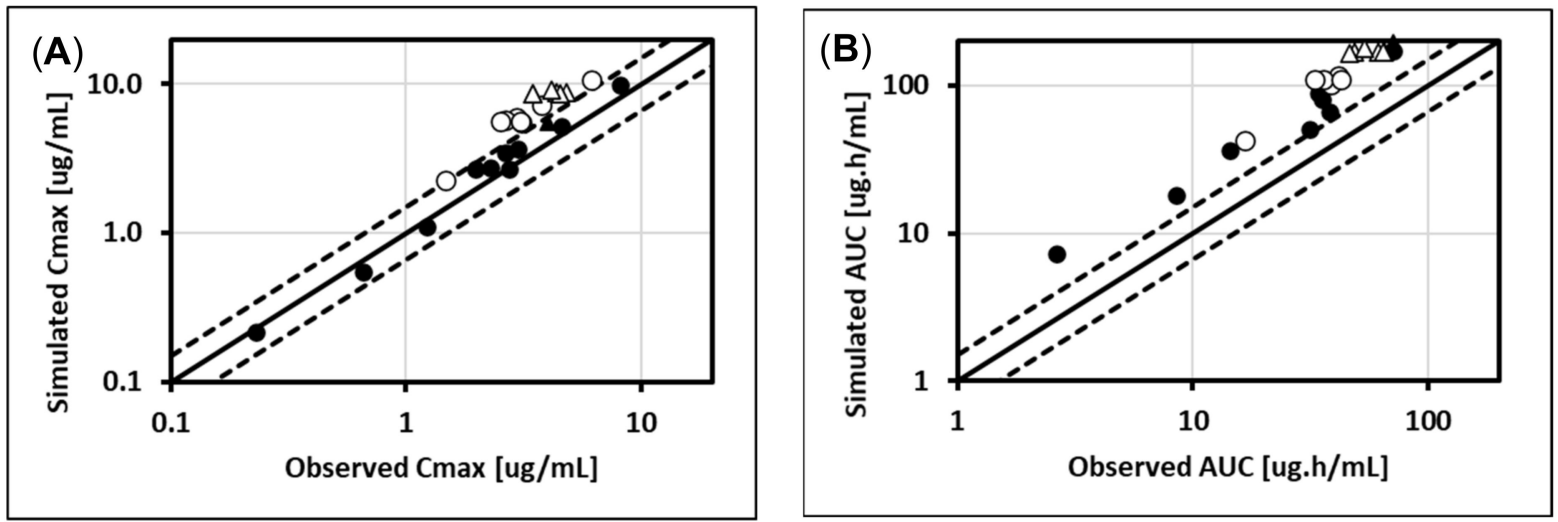

Figure 2. Cont. 

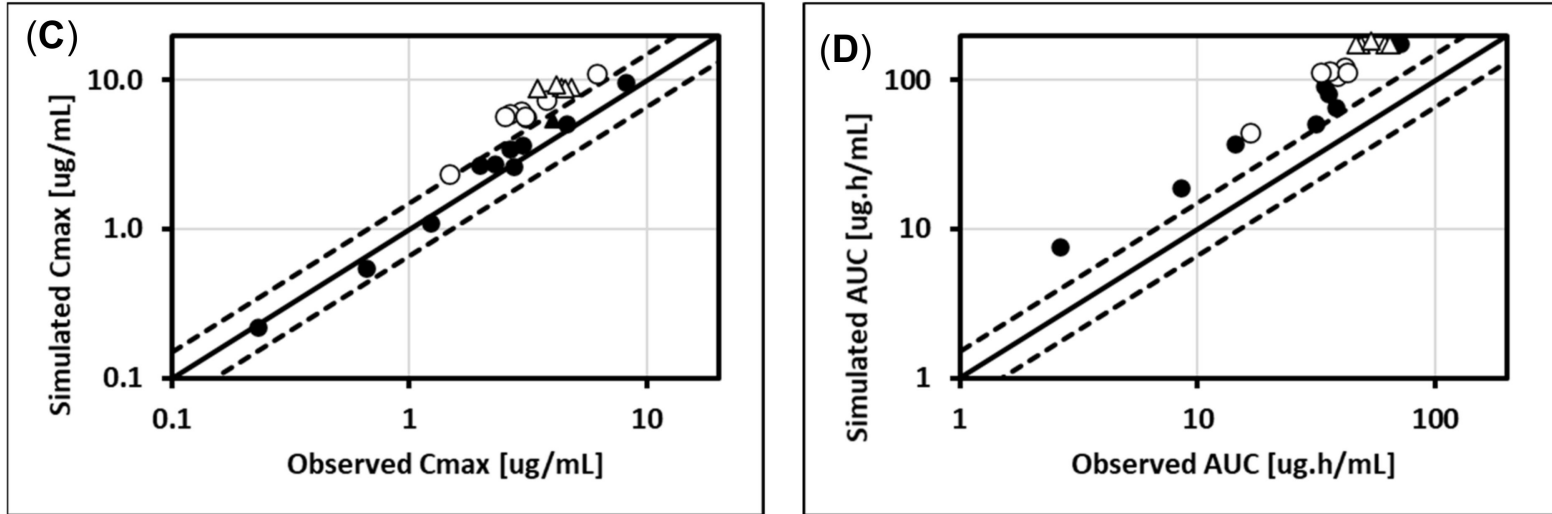

Figure 2. Comparison of simulated to observed $\mathrm{Cmax}$ and $\mathrm{AUC}\left(\mathrm{AUC}_{0-\mathrm{t}}\right.$ or $\left.\mathrm{AUC}_{\mathrm{tau}}\right)$ from different published studies $[67,68,70-$ 78] with predictions based on in vitro parameters for dolutegravir interaction with UGT1A1 measured in recombinant UGT1A1 (A,B) and in HLM (C,D). Circles represent fasted studies, triangles represent studies in which dolutegravir was administered with a moderate-fat meal, closed symbols represent single dose, and open symbols represent steady-state data. In each plot, the solid line represents the identity line, and the dashed lines show margins for 1.5-fold errors. AUC = the area under the plasma concentration-time curve, $\mathrm{AUC}_{0-\mathrm{t}}=\mathrm{AUC}$ from time zero to $\mathrm{t}, \mathrm{AUC}_{\mathrm{tau}}=\mathrm{AUC}$ during the dosing interval, $\mathrm{Cmax}=$ maximum observed total plasma concentration, and HLM = human liver microsomes.

Subsequently, the model was validated by predicting dolutegravir PK after 2-50 mg single dose administrations in fasted subjects $[67,70,71,74]$ and $10-50 \mathrm{mg}$ multiple-dose administrations in fasted $[67,70,71,73,75]$ and fed subjects [72,75-78]. The average prediction error for $\mathrm{Cmax}_{\text {and }} \mathrm{AUC}_{\mathrm{inf}}$ was 1 and $5 \%$, respectively, for studies used for model development. The average prediction error for Cmax and AUC (AUC(0-t) for single dose and AUCtau for multi-dose administrations) was 4 and $11 \%$, respectively, for studies used for model validation. The final model (Figure 3) used an in vitro $K_{m}$ measured in rUGT1A1 and Vmax values fitted against clinical data. For a $50 \mathrm{mg}$ dose of dolutegravir, nearly $18 \%$ of the dose was metabolized by the gut, with UGT1A1 contributing approximately $80 \%$ to the intestinal metabolism and CYP3A4 contributing the remaining 20\%. The contributions of intestinal metabolism came from the clearance calibration against in vivo PK profiles of dolutegravir and the default intestinal and liver expression levels of both enzymes.

After the dolutegravir PBPK model was refined and validated, it was used to predict the DDI with atazanavir, a UGT1A1 reversible inhibitor and a competitive inhibitor as well as a mechanism-based inhibitor of CYP3A4. The DDI with atazanavir [69] was predicted accurately, with predicted effect (ratio of dolutegravir Cmax and AUC when administered with atazanavir and alone) within $16 \%$ of the observed ratios of 1.54 for Cmax and 1.92 for AUC. This accurate prediction confirms the appropriate calibration of UGT1A1 intestinal contribution in the dolutegravir clearance.
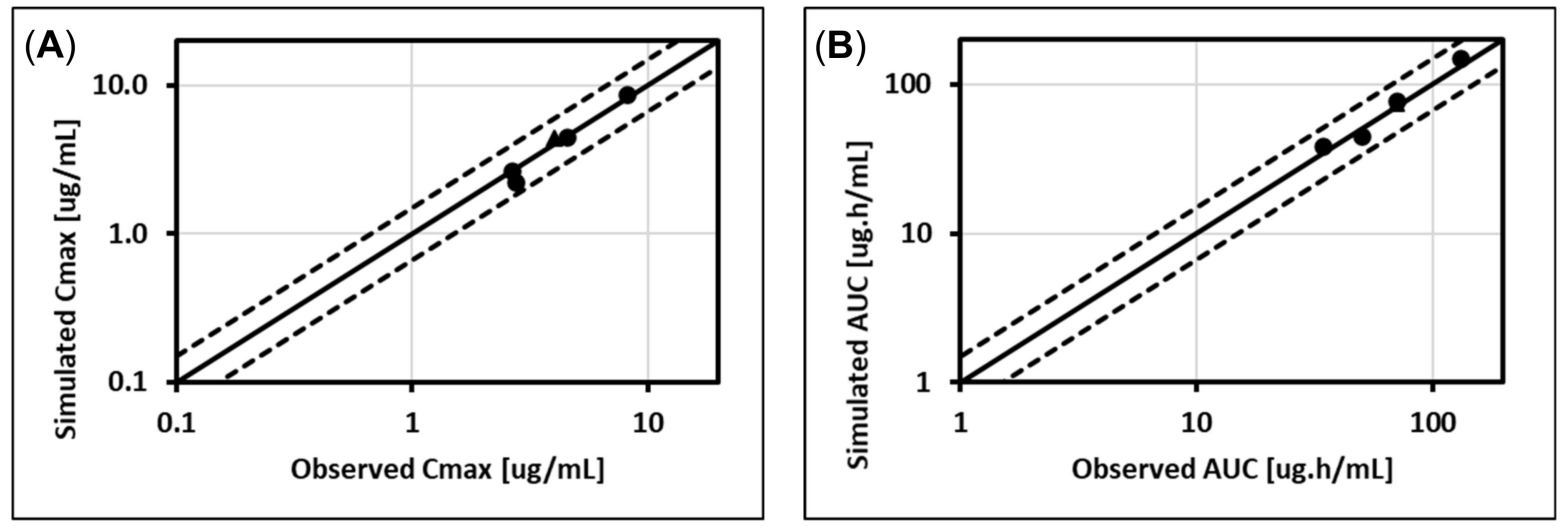

Figure 3. Cont. 

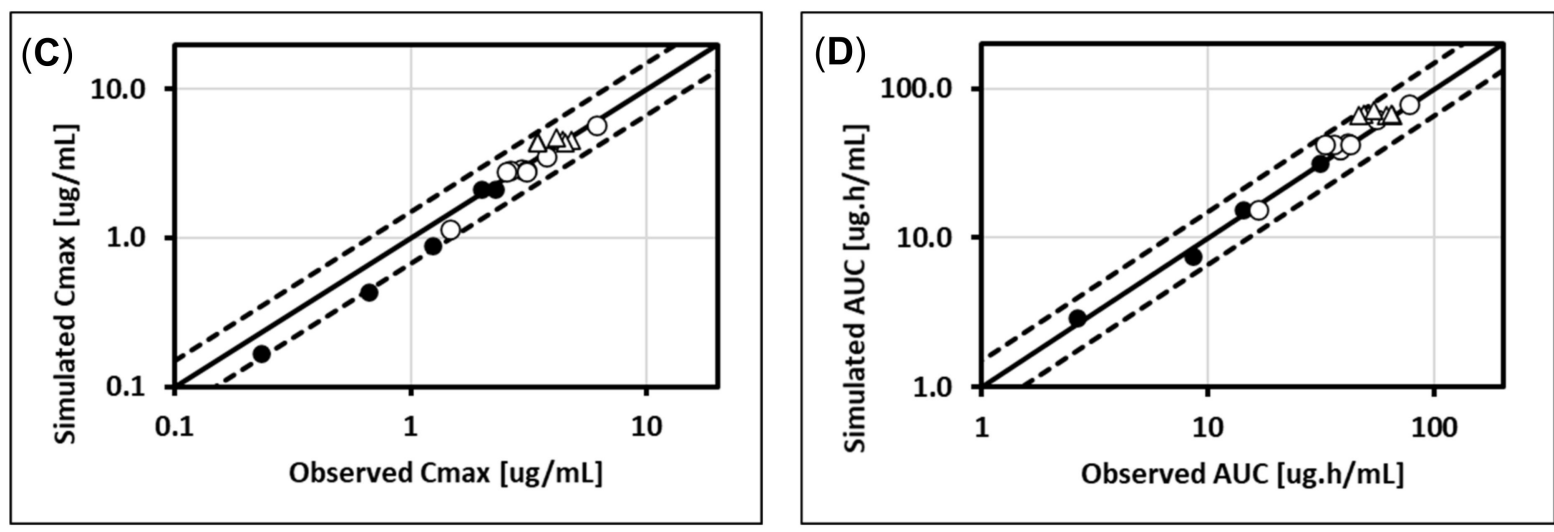

Figure 3. Comparison of observed Cmax and $A U C$ ( $\mathrm{AUC}_{0-\mathrm{t}}$ or $\mathrm{AUC}_{\mathrm{tau}}$ ) from different published studies [67,68,70-78] with final model simulations for studies used for model development (A,B) and model validation (C,D). Circles represent fasted studies, triangles represent studies where dolutegravir was administered with a moderate-fat meal, closed symbols represent single dose data, and open symbols represent steady-state data. In each plot, the solid line represents the identity line, and the dashed lines show margins for 1.5-fold errors. AUC = the area under the plasma concentration-time curve, $\mathrm{AUC}_{0-\mathrm{t}}=\mathrm{AUC}$ from time zero to $\mathrm{t}, \mathrm{AUC}_{\mathrm{tau}}=\mathrm{AUC}$ during the dosing interval, and $\mathrm{Cmax}=$ maximum observed total plasma concentration.

The PBPK atazanavir model was developed and validated using data from seven clinical studies in healthy volunteers, as described by Reddy et al. [24]. The total inhibition constant, $\mathrm{Ki}$, for UGT1A1 was $1.9 \mu \mathrm{M}$ [79] and the unbound fraction in microsomes measured in vitro of 0.502 was incorporated. For CYP3A4, the Ki was estimated using the atazanavir $\mathrm{K}_{\mathrm{m}}$ of $0.362 \mu \mathrm{M}$ [80], adjusted for microsomal binding; the mechanism-based inhibition of CYP3A4 by atazanavir was included using $\mathrm{K}_{\mathrm{I}}=0.641 \mu \mathrm{M}$; and the rate of enzyme inactivation, $\mathrm{k}_{\text {inact }}=0.114 \mathrm{~min}^{-1}$, was derived from the concentration-dependent inhibition of CYP3A4 in human liver microsomes, with and without preincubation with atazanavir [81]. Atazanavir is a hepatic uptake transporter substrate [80], and the PBPK modeling for atazanavir did not explicitly incorporate the role of transporters for atazanavir. Importantly, Nicolai et al. [82] studied the interplay of transporters and metabolism for atazanavir in rats in vitro, and found that involvement of active uptake transport did not cause high intracellular levels in this case. For atazanavir, they found that the ratio of unbound intracellular to extracellular concentration in hepatocytes was approximately 0.3 , and likewise, the unbound Michaelis-Menten constant, $\mathrm{K}_{\mathrm{m}, \mathrm{u}}$, was $>$ three-fold higher in hepatocytes than microsomes. For this reason, Ki values for atazanavir observed in vitro can depend on the system used. But the ability to predict the DDI between atazanavir and dolutegravir, and raltegravir (see Section 5.4), improves confidence in the atazanavir model.

The dolutegravir final model provided an excellent description of its PK, but the clinical PK data and ADME data were necessary to properly calibrate the elimination due to uncertainties in the reported in vitro values as well as the contribution of CYP3A4 to dolutegravir metabolism, for which no in vitro data were available. Interestingly, with the in vivo $K_{m}$ value for UGT1A1 fixed at the reported in vitro $K_{m}$ value, measured in recombinant UGT, the fitted Vmax that correctly described the in vivo DGT clearance was close $\left(\sim 30 \%\right.$ lower) to the in vitro Vmax measured in HLM. The difference in $\mathrm{K}_{\mathrm{m}}$ values measured in the two in vitro systems could potentially be due to the higher nonspecific binding of dolutegravir in HLM, and the difference in Vmax values might suggest the different activity of rUGT1A1 from that of UGT1A1 in the HLM system (which might more closely resemble the in vivo activity).

\subsection{Raltegravir (UGT1A1)}

Raltegravir is an HIV-1 integrase strand transfer inhibitor also used in combination with other antiretroviral agents. The raltegravir PBPK model, described by Reddy et al. [24], 
was built using GastroPlus version 9.0. It was modified from a preliminary model provided by Simulations Plus.

The raltegravir model incorporated in vitro and in vivo data, with a focus on matching available clinical PK and ADME data. The model incorporated clearance of raltegravir through UGT1A1 metabolism (mainly through hepatic metabolism, since UGT1A1 expression in the kidney is relatively low [30]) and renal elimination ( $9 \%$ estimated as $\mathrm{fu} \times \mathrm{GFR})$ based on human ADME data described in the Isentress ${ }^{\circledR}$ label [83]. UGT1A1-mediated intestinal metabolism was incorporated in the model through specifying UGT1A1 expression in the gut (default parameters, see Section 3). The UGT1A1 $\mathrm{K}_{\mathrm{m}}$ value for raltegravir was based on an in vitro measurement [84]. However, the Vmax values for the liver and gut were optimized to match clinical data. Raltegravir PK data exhibited significant differences (up to three-fold) in exposures between studies. It was assumed that the differences in exposure were likely due to differences in absorption, i.e., related to different formulations; therefore, for studies with significantly lower exposures ( three-fold), properties leading to poor absorption (i.e., higher particle radius and decreased solubility) were assumed.

The raltegravir model was developed to determine whether the DDI with UGT1A1 inhibitor atazanavir could be predicted. Details of the atazanavir model are described in [24], but a brief description is provided in Section 5.3. In general, the predicted increase in raltegravir exposures observed with atazanavir coadministration was reasonably accurate (Table 3), although the impact of the DDI was somewhat overestimated. Simulations indicate that the main reason atazanavir increases raltegravir exposures is the inhibition of raltegravir intestinal metabolism. For example, for the Zhu et al. [85] study, simulations indicate that $\mathrm{Fg}$ increased from $51-52 \%$ without, to $87 \%$ with atazanavir coadministration.

Table 3. Effects of atazanavir on raltegravir PK in clinical DDI studies ${ }^{1}$.

\begin{tabular}{|c|c|c|c|c|c|c|}
\hline Study & $\begin{array}{l}\text { Atazanavir } \\
\text { Dose, mg }\end{array}$ & $\begin{array}{c}\text { Raltegravir Dose, } \\
\text { mg }\end{array}$ & $\begin{array}{c}\text { Observed } \\
\mathbf{R}_{\mathrm{Cmax}}\end{array}$ & $\begin{array}{c}\text { Observed } \\
\mathbf{R}_{\text {AUC }}\end{array}$ & $\begin{array}{l}\text { Simulated } \\
\mathbf{R}_{\mathrm{Cmax}}\end{array}$ & $\begin{array}{c}\text { Simulated } \\
\mathbf{R}_{\text {AUC }}\end{array}$ \\
\hline Iwamoto et al. [86] & 400 QD & 100 & 1.53 & 1.72 & $1.8-1.9$ & $2.0-2.1$ \\
\hline Neely et al. [87] ${ }^{2}$ & $0 / 400 \mathrm{QD}^{2}$ & $400 \mathrm{BID} / 400 \mathrm{QD}^{2}$ & 1.32 & 1.37 & 1.8 & $1.7-1.8$ \\
\hline Zhu et al. [85] & 300 BID & 400 BID & 1.54 & 1.54 & $1.8-1.9$ & $1.8-2.0$ \\
\hline
\end{tabular}

${ }^{1}$ BID = twice daily, DDI = drug-drug interaction, QD = once daily, PK = pharmacokinetics, $\mathrm{R}_{\mathrm{Cmax}}=$ ratio of the Cmax value with atazanavir co-administered to the value without atazanavir co-administered, and $\mathrm{R}_{\mathrm{AUC}}=$ ratio of the AUC value with atazanavir co-administered to the value without atazanavir co-administered. ${ }^{2}$ The study compared raltegravir exposures when administered as a single agent at a dose of $400 \mathrm{mg}$ BID compared to a dose of $400 \mathrm{mg}$ QD when co-administered with atazanavir at a dose of $400 \mathrm{mg}$ QD.

\section{Discussion}

\subsection{Prediction of Intestinal Metabolism Mediated by UGTs with PBPK Modeling}

The importance of intestinal metabolism to oral bioavailability is well studied but mainly for CYP substrates. For CYP3A4 substrates, many factors contributed to the success of developing PBPK modeling as a tool for predicting Fg. Yang et al. [4] developed a modeling approach to predict intestinal metabolism for CYP3A4 substrates using clinical data from the literature. They noted three types of studies that could be used to study the impact of CYP3A4 on oral bioavailability: (1) anhepatic patients, (2) comparison of exposure from IV and oral PK, and (3) comparison of PK with and without an inhibitor (e.g., studies with grapefruit juice co-administration, which at the right dose is thought to inhibit mainly intestinal CYP3A4) [4]. In vivo intestinal metabolism of midazolam (a CYP3A4 substrate) was studied following IV and intraduodenal administration during the anhepatic phase of liver transplantation [88]. However, to our knowledge, data for any UGT substrates in anhepatic patients do not exist. The grapefruit juice study also does not apply since it does not inhibit UGTs in the same way as for CYP3A4. Moreover, there are limited PK data for administration of UGT substrates by both IV and oral (PO) routes that can be compared for the determination of Fg (see examples in Section 6.2). Here, we propose a similar approach, which has been used to great effect for CYP3A4 substrates, but apply it to UGTs. 
UGT substrates are often thought of as having low clearance. While this is often the case, UGT-mediated intestinal metabolism can significantly reduce exposure. The prediction of intestinal metabolism based on nonclinical data is critical for selecting a compound likely to achieve acceptable exposure in the clinic. Additionally, predicting intestinal metabolism is important for assessing a compound's DDI liabilities [3]. Here, we described the use of PBPK models to predict intestinal metabolism, including underlying data such as expression levels in the intestines, and reviewed examples utilizing PBPK modeling to understand the extent of intestinal metabolism for drugs that undergo UGT metabolism.

\subsection{Clinical Relevance of UGT Intestinal Metabolism}

Clinical IV and PO PK data from the literature have been reported for UGT substrates, and were used to calculate Fg (with values either reported or determined using standard equations described by Kharasch et al. [89]), with results provided in Table 4. Mizuma et al. [12] described a greater impact of intestinal glucuronidation than hepatic glucuronidation on the bioavailability of raloxifene, a UGT1A1, 1A8, 1A9, and 1A10 substrate. Based on the reported human data of raloxifene, this study estimated an absolute $\mathrm{F}$ of 0.02 with an $\mathrm{Fa}$ of $0.63, \mathrm{Fg}$ of 0.054 , and $\mathrm{Fh}$ of 0.593 [12]. Estimated $\mathrm{Fg}$ values for other UGT substrates have also been reported in the literature $[20,90]$ and are listed in Table 4. This analysis provides another way of estimating intestinal metabolism for UGT substrates but provides limited insight in compound properties leading to first-pass metabolism.

Interestingly, for substrates including raloxifene, troglitazone, and diclofenac, Fg values are lower than Fh values, indicating greater first-pass loss from intestinal metabolism than from hepatic metabolism. An in vitro study identified UGT1A1 and 1A10 [91] as the enzymes responsible for the glucuronidation of troglitazone. UGT1A10 exhibited high catalytic activity and is expressed only in extrahepatic tissues (e.g., intestine and colon), which explains the low calculated $\mathrm{Fg}$ value for this compound. The major enzyme responsible for glucuronidation of diclofenac was UGT2B7, followed by $1 \mathrm{~A} 9$ and $1 \mathrm{~A} 6=2 \mathrm{~B} 15$ [92]. The subfamilies of UGT1A and UGT2B are expressed in both liver and intestine (see Section 3). The relatively high expression of UGT2B7 in the intestines seemingly resulted in a lower Fg value than Fh value for diclofenac [90]. In the case of acyl-glucuronide formation (e.g., gemfibrozil) enterohepatic circulation has been demonstrated due to the gut hydrolysis of the labile acyl-glucuronide, which may have resulted in $\mathrm{Fa}>1.0$. For example, the $\mathrm{Fg}=1.09$ for gemfibrozil in Table 4 is likely a reflection of an increase in Fa $>1.0$. The estimation of $\mathrm{Fg}$ from clinical IV and PO PK data for these examples illustrates the range of potential impact of UGT-mediated intestinal metabolism on oral bioavailability.

This analysis also demonstrates that care is needed in interpretation of the Fg calculated using this method. For example, in the case of canagliflozin, the calculated Fg of 0.75 suggests that canagliflozin undergoes intestinal metabolism. However, canagliflozin is primarily metabolized by UGT1A9 and UGT2B4, and these isoforms are not expressed in the intestine [8]. Several assumptions in these calculations can lead to the over-estimation of intestinal metabolism, as has been discussed before [93]. In the case of canagliflozin, the discrepancy could be due to the assumed Fa of 1, which may well be an over-estimation given that canagliflozin is a BCS class IV molecule [94].

A clinical DDI study with a UGT inducer such as rifampin may not, by itself, be able to elucidate the contribution of intestinal metabolism for UGT substrates. For example, in DDI studies with rifampin, AUC for canagliflozin and raltegravir were reduced to a similar extent: 51\% [95] and 40\% [96], respectively. However, there are differences in the calculated Fg of 0.75 for canagliflozin (Table 4 ) vs. $\sim 0.5$ for raltegravir (Table 2). This example further highlights the challenges in elucidating the contribution of intestinal metabolism on a drug's disposition. As such, a combination of PBPK modeling, use of mechanistic in vitro studies, and carefully designed clinical DDI studies may be used to better understand the underlying processes for intestinal first-pass effects. 
Table 4. Summary of F, Fa, Fg, and Fh Values for UGT Substrates in Humans ${ }^{1}$.

\begin{tabular}{|c|c|c|c|c|c|c|c|}
\hline Name & $\mathbf{F}$ & $\mathrm{Fa}$ & Fg & Fh & UGTs Involved & $\begin{array}{c}\text { Intestinal } \\
\text { Metabolism? }\end{array}$ & Reference \\
\hline Canagliflozin & 0.65 & $1^{3}$ & $0.75^{4}$ & 0.86 & UGT1A9, UGT2B4 & No & Devineni et al. [94] \\
\hline Dapagliflozin & 0.78 & $1^{3}$ & 0.90 & 0.86 & UGT1A9, UGT2B7 & Yes & Boulton et al. [97] \\
\hline Diclofenac & 0.54 & $1^{3}$ & 0.64 & 0.85 & $\begin{array}{l}\text { UGT2B7, } \\
\text { UGT1A9, } \\
\text { UGT1A6, } \\
\text { UGT2B15 }\end{array}$ & Yes & Varma et al. [90] \\
\hline Ertugliflozin & 1.05 & 1.11 & 1.08 & 0.88 & $\begin{array}{c}\text { UGT1A9, } \\
\text { UGT2B4, UGT2B7 }\end{array}$ & Yes & Raje et al. [98] \\
\hline Gemfibrozil & 0.98 & $1^{3}$ & 1.09 & 0.90 & UGT2B7 & Yes & Nishimuta et al. [20] \\
\hline Lorazepam & 0.93 & $1^{3}$ & 0.97 & 0.96 & $\begin{array}{l}\text { UGT2B4, UGT2B7, } \\
\text { UGT2B15 }\end{array}$ & Yes & Varma et al. [90] \\
\hline Raloxifene & 0.02 & 0.63 & 0.054 & 0.593 & $\begin{array}{l}\text { UGT1A1, } \\
\text { UGT1A8, } \\
\text { UGT1A9, } \\
\text { UGT1A10 } 5\end{array}$ & Yes & Mizuma [12] \\
\hline Troglitazone & 0.45 & $1^{3}$ & 0.56 & 0.80 & $\begin{array}{l}\text { UGT1A1, } \\
\text { UGT1A10 }\end{array}$ & Yes & Nishimuta et al. [20] \\
\hline Lorazepam & 0.93 & $1^{3}$ & 0.97 & 0.96 & $\begin{array}{c}\text { UGT2B4, UGT2B7, } \\
\text { UGT2B15 }\end{array}$ & Yes & Varma et al. [90] \\
\hline Telmisartan & 0.43 & 0.90 & 0.75 & 0.64 & $\begin{array}{l}\text { UGT1A1, } \\
\text { UGT1A3, } \\
\text { UGT1A9 }\end{array}$ & Yes & Varma et al. [90] \\
\hline Oxazepam & 0.93 & 0.93 & 1.01 & 0.99 & $\begin{array}{l}\text { UGT1A9, } \\
\text { UGT2B7, } \\
\text { UGT2B15 }\end{array}$ & Yes & Varma et al. [90] \\
\hline
\end{tabular}

${ }^{1}$ Numbers were either taken as reported or calculated using the approach of Kharasch et al. [89], reported Fa (or assumed 1 in the absence of a reported value), and a liver blood flow rate of $1.5 \mathrm{~L} / \mathrm{min}$ [99]. F = bioavailability, Fa $=$ fraction absorbed, FDp $=$ fraction of dose passing into the portal vein, $\mathrm{Fg}=$ fraction of drug escaping first-pass intestinal metabolism, and Fh $=$ hepatic availability. ${ }^{2}$ Based on UGT expression in intestine from Basit et al. [8]. ${ }^{3} \mathrm{Fa}$ was assumed to be 1 . In this case the Fg actually represented FDp (= Fa $\times$ Fg). ${ }^{4}$ Canagliflozin Fg is most likely underestimated, since UGT1A9 and UGT2B4 are not expressed in the intestines. ${ }^{5}$ For raloxifene, SULT1E1 contributes to metabolism, but intestinal metabolism is thought to be mainly due to glucuronidation by UGT1A1, 1A8, and 1A10 [100].

Intestinal metabolism can be important from a DDI perspective. The raltegravir example (Section 5.4) highlights the role of intestinal metabolism in the DDI with the UGT1A1 inhibitor atazanavir. However, DDIs with rifampin, even when intestinal metabolism plays a role, do not seem to be as significant for UGT substrates as for CYP3A substrates. PBPK modeling is a potentially useful tool for assessing the DDI risk for UGT substrates, although limited probe substrates and well-characterized perpetrators are available for model qualification.

\subsection{Limitations of the PBPK Approach for Predicting Fg for UGT Substrates}

Data for UGT1A1 expression in the GI tract are reasonably consistent across studies, and therefore PBPK modeling for UGT1A1 intestinal metabolism has a stronger foundation than for other UGTs (e.g., UGT1A4, UGT1A6, UGT1A9, UGT2B7, and UGT2B17), for which existing expression data are less consistent (Table 1). In the modeling work of Docci et al. [23], initial predicted oral clearance based on IVIVE was within two-fold for lorazepam (substrate of UGT2B7 and UGT2B15), oxazepam (substrate of UGT1A9 and UGT2B15), and zidovudine (substrate of UGT2B7 and CYP3A4), but bioavailability was underestimated until Vmax values were scaled with an empirical factor of 0.25 to reduce the predicted first-pass metabolism in the gut. As additional intestinal expression data and 
modeling work becomes available, PBPK modeling for all the UGTs expressed in the GI tract will be strengthened by capitalizing on this systems biology approach.

Parameterizing saturable metabolism, which can be important for intestinal metabolism, particularly for high-dose compounds with high concentrations in the GI tract, can be a challenge for PBPK modeling of intestinal metabolism. Heikkinen et al. [6] evaluated the accuracy and precision of GastroPlus Fg predictions for a set of 20 CYP3A substrates using in vitro and in silico inputs. Overall, good Fg prediction accuracy was found (no significant bias and $95 \%$ of predictions within two-fold from in vivo estimated $\mathrm{Fg}$ ), but the precision was limited, especially for high extraction compounds. Given the challenges of studying the metabolism of UGT substrates in vitro (see Section 4 and the dolutegravir example in Section 5.3), confidence in a Km estimate may be limited. Parameter sensitivity analysis for $\mathrm{Km}$ and for parameters impacting local drug concentrations in the GI tract (e.g., solubility, dissolution) may be important for understanding the impact of uncertainty on the Fg estimate. Therefore, in the early stages of drug development, a bottom-up PBPK approach to identify potential uncertainties and their impact on predictions would be recommended [2], but once clinical data are available the PBPK model may be refined via top-down fitting of nonlinearity (i.e., adjusting $\mathrm{Km}$ based on fitting to dose-dependent PK).

The modeling examples presented here are all relatively simple, for drugs that form primary glucuronide conjugates. The models did not include enterohepatic recirculation or transporter-mediated mass transfer, which may be needed for glucuronide conjugate metabolites to be included in the modeling. However, these models provide a foundation for others to build on with more complex examples.

Of course, applying PBPK modeling requires a solid understanding of the PK properties of a compound. To apply PBPK modeling prospectively before clinical data are available results in greater uncertainty. However, even when clinical data are available, the lack of specific types of data (e.g., mechanistic in vitro ADME data, human IV PK data, or human ADME study data may not be available) may lead to uncertainty $[2,101]$. Nonetheless, the examples presented in this paper show PBPK model utility for understanding intestinal metabolism for UGT substrates using an IVIVE approach as well as based mainly on clinical data.

\subsection{In Silico Example: Predicted Substrate Specificity for UGT Enzymes}

Knowing that a compound is subject to metabolism by Phase I, Phase II, or hydrolytic cleavage is key to understanding its bioavailability and, if it is a prodrug, its bioactivation. Prediction of which metabolites are most likely produced by these metabolic mechanisms is also critical to understanding the toxicology, efficacy, and pharmacokinetic properties of drug candidates. All the UGT substrates included in the examples in this publication have aliphatic or aromatic hydroxyl groups and do not require phase I metabolism prior to conjugation.

The Metabolism Module of ADMET Predictor ${ }^{\circledR}$ (Simulations Plus, Inc., Lancaster, CA, USA) provides substrate classification models for nine human UGT isoforms. Much more data are available for CYP enzymes, and correspondingly, more detailed models are available for CYPs, including models for estimating kinetic parameters as well as ones for substrate and inhibitor classification. Substrate classification models are provided for human UGTs 1A1, 1A3, 1A4, 1A6, 1A8, 1A9, 1A10, 2B7, and 2B15. These models are classification artificial neural network ensemble models based on substrate specificity data from about 270 publicly available literature sources (e.g., [102,103]). The number of compounds used to train these nine models ranged from 196 to 319. Unfortunately, the combination of complex kinetics and scarcity of suitable data for UGT enzymes precludes the ability to provide kinetic models or estimate clearance for UGT enzymes. However, in silico models included with ADMET Predictor can generate a schematic map of metabolites most likely to be generated for each UGT for compounds that are predicted to be substrates of a given UGT. 
For all drugs described in this manuscript and two more with well-characterized metabolism (canagliflozin and tapentadol), Table 5 provides the in silico predictions of substrate specificities for nine UGT enzymes (UGT1A1, UGT1A3, UGT1A4, UGT1A6, UGT1A8, UGT1A9, UGT1A10, UGT2B7, and UGT2B15). For each enzyme, the table includes "Yes $/ \mathrm{No}^{\prime}$ results regarding the predicted substrate specificity and includes " $\%$ confidence)" that the classification model is accurate. The results are outlined with a red colored square for false positives, a green background for true positives, and a red "Yes/No" for molecules that were out of scope for that prediction. For example, cabotegravir was accurately predicted to be a substrate of UGT1A1 and UGT1A9 but also had a false positive substrate prediction for UGTs 1A8, 1A10, 2B7, and 2B15. It should be noted that the classification accuracy was very low at 56 and 52\% for 1A10 and 2B15, respectively, and so the predictions may be less reliable. Only two molecules out of nine (canagliflozin and oxazepam) did not have an accurate prediction of substrate specificity. Only five out of 43 negative predictions were false negatives (i.e., predicted to not be substrates for enzymes with experimental proof of substrate specificity), but 38 out of 43 negative predictions were true negatives.

Table 5. In Silico Substrate Classification for Example UGT Substrates ${ }^{1}$.

\begin{tabular}{|c|c|c|c|c|c|c|c|c|c|}
\hline $\begin{array}{c}\text { Substrate of }{ }^{2} \text { : } \\
\text { Overall Accuracy }\end{array}$ & $\begin{array}{c}\text { UGT1A1 } \\
85 \%\end{array}$ & $\begin{array}{l}\text { UGT1A3 } \\
\quad 85 \%\end{array}$ & $\begin{array}{l}\text { UGT1A4 } \\
\quad 88 \%\end{array}$ & $\begin{array}{l}\text { UGT1A6 } \\
85 \%\end{array}$ & $\begin{array}{c}\text { UGT1A8 } \\
87 \%\end{array}$ & $\begin{array}{c}\text { UGT1A9 } \\
88 \%\end{array}$ & $\begin{array}{c}\text { UGT1A10 } \\
85 \%\end{array}$ & $\begin{array}{c}\text { UGT2B7 } \\
84 \%\end{array}$ & $\begin{array}{c}\text { UGT2B15 } \\
91 \%\end{array}$ \\
\hline Cabotegravir (UGT1A1, UGT1A9) & Yes $(96 \%)$ & No $(78 \%)$ & No $(99 \%)$ & No $(97 \%)$ & $\underline{\text { Yes }}$ & Yes $(88 \%)$ & Yes $(56 \%)$ & Yes $(80 \%)$ & Yes $(52 \%)$ \\
\hline Canagliflozin (UGT1A9, UGT2B4) & No $(50 \%)$ & No $(66 \%)$ & Yes $(89 \%)$ & No $(83 \%)$ & No $(98 \%)$ & No $(96 \%)$ & No $(75 \%)$ & No $(70 \%)$ & No $(92 \%)$ \\
\hline Dolutegravir (UGT1A1) & Yes $(96 \%)$ & No $(78 \%)$ & No $(99 \%)$ & No $(97 \%)$ & $\underline{\text { Yes }}$ & Yes $(62 \%)$ & Yes $(56 \%)$ & Yes $(80 \%)$ & Yes $(58 \%)$ \\
\hline Lorazepam (UGT2B7, UGT2B15) & No $(95 \%)$ & No $(92 \%)$ & No $(66 \%)$ & No $(97 \%)$ & Yes $(81 \%)$ & No $(96 \%)$ & Yes $(71 \%)$ & Yes $(80 \%)$ & No $(82 \%)$ \\
\hline Naloxone (UGT2B7) & No $(99 \%)$ & Yes $(53 \%)$ & No $(99 \%)$ & No $(97 \%)$ & Yes $(72 \%)$ & No $(96 \%)$ & No $(97 \%)$ & Yes $(93 \%)$ & No $(98 \%)$ \\
\hline Oxazepam (UGT1A9, UGT2B15) & No $(97 \%)$ & No $(92 \%)$ & Yes $(45 \%)$ & No $(88 \%)$ & No $(63 \%)$ & No $(96 \%)$ & Yes $(64 \%)$ & Yes $(93 \%)$ & No $(98 \%)$ \\
\hline Raltegravir (UGT1A1) & Yes $(90 \%)$ & No $(49 \%)$ & No $(99 \%)$ & No $(91 \%)$ & Yes $(75 \%)$ & Yes $(73 \%)$ & No $(70 \%)$ & Yes $(74 \%)$ & $\underline{\text { Yes }}$ \\
\hline Tapentadol (UGT1A9, UGT2B7) & No $(99 \%)$ & Yes $(90 \%)$ & Yes $(59 \%)$ & No $(97 \%)$ & Yes $(78 \%)$ & Yes $(97 \%)$ & No $(90 \%)$ & Yes $(85 \%)$ & No $(67 \%)$ \\
\hline Zidovudine (UGT2B7) & No $(98 \%)$ & No $(98 \%)$ & No $(95 \%)$ & No $(97 \%)$ & No & No $(69 \%)$ & No $(97 \%)$ & Yes $(66 \%)$ & No $(84 \%)$ \\
\hline
\end{tabular}

${ }^{1}$ Calculations were done for each of the drugs in the far-left column, with the UGTs thought to metabolize them shown in (). "Yes" or "No" indicates whether the drug is predicted to be a substrate of each enzyme, and "(\% confidence)" indicates how likely it is that the classification model is accurate, according to the algorithm. The results are outlined with a red colored square for false positives, a green background for true positives, a tan colored background for false negatives, and a red "Yes/No" for molecules that were out of scope for that prediction (for which confidence was not determined). ${ }^{2}$ Calculation addresses the question of whether the drugs are substrates of these UGTs (Yes/No), and \% confidence that answer is correct.

Overall, it can be concluded that the purely in silico predictions for UGT substrate specificity are quite accurate and would be useful in planning a limited number of additional experiments for confirmation. The results are encouraging and show promise for pure in silico predictions but will need to be confirmed with a larger set of compounds. Combining this in silico assessment with understanding of metabolite stability and knowledge of UGT expression in the GI tract may allow an initial assessment, qualitative and perhaps even quantitative through PBPK modeling, of the likelihood of decreased exposures from first-pass extraction due to intestinal metabolism.

\section{Conclusions}

PBPK modeling has become an important tool for estimating intestinal metabolism for CYP3A substrates, and here, we show that this valuable method can be used for UGT substrates. Protein and mRNA level data are available to estimate intestinal, hepatic, and renal UGT expression levels. Estimates for UGT1A1 expression in the intestines are reasonably consistent across several sources of experimental data, but for the other UGT enzymes, data are more limited and less consistent. As more is learned about the expression of UGTs, the parameters will be refined to leverage this systems biology approach. Although there are challenges in studying metabolism in vitro for UGT substrates, advances, such as coculture models including $\mathrm{H} \mu \mathrm{rel}^{\circledR}$ and HepatoPac ${ }^{\circledR}$ for low clearance compounds and better understanding of the best conditions for in vitro studies of UGT substrate metabolism, may provide opportunities for improved IVIVE. PBPK modeling has been shown to be 
a useful tool for modeling the intestinal metabolism of UGT substrates to understand compound properties contributing to first-pass losses, but additional examples with IVIVE would build confidence in prospective predictions. PBPK modeling shows promise as an increasingly useful tool for predicting first-pass loss from intestinal metabolism for UGT substrates.

Author Contributions: Conceptualization, M.B.B., A.T.H., L.L., N.P., M.B.R. and V.L.; background and review, A.T.H. and G.F.; case studies, L.D.F., V.L., J.M.M., N.P. and M.B.R.; discussion, M.B.B., J.S.M., A.M. and M.B.R.; writing—original draft preparation, review and editing, all authors; supervision (only for this collaboration), M.B.R. All authors have read and agreed to the published version of the manuscript.

Funding: This research received no external funding, except the journal fees which were paid by Simulations Plus.

Institutional Review Board Statement: Not applicable.

Informed Consent Statement: Not applicable.

Data Availability Statement: Not applicable.

Acknowledgments: The authors thank Bob Clark for helping describe to the development of the UGT substrate classification models. We also thank Kevin Litwiler for his review and helpful comments.

Conflicts of Interest: M.B.R. worked for Array BioPharma at the time she worked on modeling for raltegravir and atazanavir, and she currently works for Pfizer. G.F., J.S.M., J.M.M., M.B.B., N.M. and V.L. work for Simulations Plus, the software company of GastroPlus. Journal fees were also paid by Simulations Plus. The manuscript reflects the views of the scientists, and not the company.

\section{References}

1. Jones, H.M.; Parrott, N.; Jorga, K.; Lavé, T. A Novel strategy for physiologically based predictions of human pharmacokinetics. Clin. Pharm. 2006, 45, 511-542. [CrossRef]

2. Miller, N.A.; Reddy, M.B.; Heikkinen, A.T.; Lukacova, V.; Parrott, N. Physiologically based pharmacokinetic modelling for first-in-human predictions: An updated model building strategy illustrated with challenging industry case studies. Clin. Pharm. 2019, 58, 727-746. [CrossRef]

3. Alqahtani, S.; Bukhari, I.; Albassam, A.; Alenazi, M. An update on the potential role of intestinal first-pass metabolism for the prediction of drug-drug interactions: The role of PBPK modeling. Expert Opin. Drug Met. Toxicol. 2018, 14, 625-634. [CrossRef]

4. Yang, J.; Jamei, M.; Yeo, K.R.; Tucker, G.T.; Rostami-Hodjegan, A. Prediction of intestinal first-pass drug metabolism. Curr. Drug Metab. 2007, 8, 676-684. [CrossRef] [PubMed]

5. Heikkinen, A.T.; Fowler, S.; Gray, L.; Li, J.; Peng, Y.; Yadava, P.; Railkar, A.; Parrott, N. In vitro to in vivo extrapolation and physiologically based modeling of cytochrome P450 mediated metabolism in beagle dog gut wall and liver. Mol. Pharm. 2013, 10, 1388-1399. [CrossRef] [PubMed]

6. Heikkinen, A.T.; Baneyx, G.; Caruso, A.; Parrott, N. Application of PBPK modeling to predict human intestinal metabolism of CYP3A substrates-An evaluation and case study using GastroPlus ${ }^{\mathrm{TM}}$. Eur. J. Pharm. Sci. 2012, 47, 375-386. [CrossRef]

7. Karlsson, F.H.; Bouchene, S.; Hilgendorf, C.; Dolgos, H.; Peters, S.A. Utility of in vitro systems and preclinical data for the prediction of human intestinal first-pass metabolism during drug discovery and preclinical development. Drug Metab. Dispos. 2013, 41, 2033-2046. [CrossRef] [PubMed]

8. Basit, A.; Neradugomma, N.K.; Wolford, C.; Fan, P.W.; Murray, B.; Takahashi, R.H.; Khojasteh, S.C.; Smith, B.J.; Heyward, S.; Totah, R.A.; et al. Characterization of differential tissue abundance of major non-CYP enzymes in human. Mol. Pharm. 2020, 17, 4114-4124. [CrossRef]

9. Harbourt, D.E.; Fallon, J.K.; Ito, S.; Baba, T.; Ritter, J.K.; Glish, G.L.; Smith, P.C. Quantification of human uridine-diphosphate glucuronosyl transferase $1 \mathrm{~A}$ isoforms in liver, intestine, and kidney using nanobore liquid chromatography-tandem mass spectrometry. Anal. Chem. 2011, 84, 98-105. [CrossRef]

10. Ohno, S.; Nakajin, S. Determination of mRNA expression of human UDP-glucuronosyltransferases and application for localization in various human tissues by real-time reverse transcriptase-polymerase chain reaction. Drug Metab. Dispos. 2009, 37, 32-40. [CrossRef]

11. Sato, Y.; Nagata, M.; Tetsuka, K.; Tamura, K.; Miyashita, A.; Kawamura, A.; Usui, T. Optimized methods for targeted peptide-based quantification of human uridine $5^{\prime}$-diphosphate-glucuronosyltransferases in biological specimens using liquid chromatographytandem mass spectrometry. Drug Metab. Dispos. 2014, 42, 885-889. [CrossRef] [PubMed] 
12. Mizuma, T. Intestinal glucuronidation metabolism may have a greater impact on oral bioavailability than hepatic glucuronidation metabolism in humans: A study with raloxifene, substrate for UGT1A1, 1A8, 1A9, and 1A10. Int. J. Pharm. 2009, 378, 140-141. [CrossRef]

13. Ge, S.; Tu, Y.; Hu, M. Challenges and opportunities with predicting in vivo Phase II metabolism via glucuronidation from in vitro data. Curr. Pharm. Rep. 2016, 2, 326-338. [CrossRef]

14. Argikar, U.A.; Potter, P.M.; Hutzler, J.M.; Marathe, P.H. Challenges and opportunities with non-CYP enzymes aldehyde oxidase, carboxylesterase, and UDP-glucuronosyltransferase: Focus on reaction phenotyping and prediction of human clearance. AAPS J. 2016, 18, 1391-1405. [CrossRef] [PubMed]

15. Naritomi, Y.; Nakamori, F.; Furukawa, T.; Tabata, K. Prediction of hepatic and intestinal glucuronidation using in vitro-in vivo extrapolation. Drug Metab. Pharm. 2015, 30, 21-29. [CrossRef] [PubMed]

16. Docci, L.; Klammers, F.; Ekiciler, A.; Molitor, B.; Umehara, K.; Walter, I.; Krähenbühl, S.; Parrott, N.; Fowler, S. In vitro to in vivo extrapolation of metabolic clearance for UGT substrates using short-term suspension and long-term co-cultured human hepatocytes. AAPS J. 2020, 22, 131. [CrossRef]

17. McGinnity, D.F.; Soars, M.G.; Urbanowicz, R.A.; Riley, R.J. Evaluation of fresh and cryopreserved hepatocytes as in vitro drug metabolism tools for the prediction of metabolic clearance. Drug Metab. Dispos. 2004, 32, 1247-1253. [CrossRef]

18. Miners, J.O.; Knights, K.M.; Houston, J.B.; Mackenzie, P.I. In vitro-in vivo correlation for drugs and other compounds eliminated by glucuronidation in humans: Pitfalls and promises. Biochem. Pharm. 2006, 71, 1531-1539. [CrossRef]

19. Zientek, M.A.; Youdim, K. Reaction phenotyping: Advances in the experimental strategies used to characterize the contribution of drug-metabolizing enzymes. Drug Metab. Dispos. 2015, 43, 163-181. [CrossRef]

20. Nishimuta, H.; Sato, K.; Yabuki, M.; Komuro, S. Prediction of the intestinal first-pass metabolism of CYP3A and UGT substrates in humans from in vitro data. Drug Metab. Pharm. 2011, 26, 592-601. [CrossRef]

21. Stingl, J.C.; Bartels, H.; Viviani, R.; Lehmann, M.L.; Brockmöller, J. Relevance of UDP-glucuronosyltransferase polymorphisms for drug dosing: A quantitative systematic review. Pharm. Ther. 2014, 141, 92-116. [CrossRef] [PubMed]

22. Wu, B.; Kulkarni, K.; Basu, S.; Zhang, S.; Hu, M. First—pass metabolism via UDP—glucuronosyltransferase: A barrier to oral bioavailability of phenolics. J. Pharm. Sci. 2011, 100, 3655-3681. [CrossRef]

23. Docci, L.; Umehara, K.; Krähenbühl, S.; Fowler, S.; Parrott, N. Construction and verification of physiologically based pharmacokinetic models for four drugs majorly cleared by glucuronidation: Lorazepam, oxazepam, naloxone, and zidovudine. AAPS J. 2020, 22, 128. [CrossRef]

24. Reddy, M.B.; Lukacova, V.; Fraczkiewicz, G.; Macwan, J.S.; Del Frari, L. PBPK modeling for binimetinib to understand implications of UGT1A1-mediated metabolism for pharmacokinetics and drug-drug interactions. 2021, in press.

25. Jamei, M.; Turner, D.; Yang, J.; Neuhoff, S.; Polak, S.; Rostami-Hodjegan, A.; Tucker, G. Population-based mechanistic prediction of oral drug absorption. AAPS J. 2009, 11, 225-237. [CrossRef] [PubMed]

26. Thelen, K.; Coboeken, K.; Willmann, S.; Burghaus, R.; Dressman, J.B.; Lippert, J. Evolution of a detailed physiological model to simulate the gastrointestinal transit and absorption process in humans, part 1: Oral solutions. J. Pharm. Sci. 2011, 100, 5324-5345. [CrossRef] [PubMed]

27. Agoram, B.; Woltosz, W.S.; Bolger, M.B. Predicting the impact of physiological and biochemical processes on oral drug bioavailability. Adv. Drug Deliv. Rev. 2001, 50, S41-S67. [CrossRef]

28. Simulations Plus. Better Decisions through Better Science. User Manual for GastroPlus Version 9.8; Simulations Plus: Lancaster, CA, USA, 2020.

29. Meech, R.; Hu, D.G.; McKinnon, R.A.; Mubarokah, S.N.; Haines, A.Z.; Nair, P.C.; Rowland, A.; Mackenzie, P.I. The UDP-glycosyltransferase (UGT) superfamily: New members, new functions, and novel paradigms. Physiol. Rev. 2019, 99, 1153-1222. [CrossRef] [PubMed]

30. Margaillan, G.; Rouleau, M.; Fallon, J.K.; Caron, P.; Villeneuve, L.; Turcotte, V.; Smith, P.C.; Joy, M.S.; Guillemette, C. Quantitative profiling of human renal UDP-glucuronosyltransferases and glucuronidation activity: A comparison of normal and tumoral kidney tissues. Drug Metab. Dispos. 2015, 43, 611-619. [CrossRef] [PubMed]

31. Nishimura, M.; Ejiri, Y.; Kishimoto, S.; Suzuki, S.; Satoh, T.; Horie, T.; Narimatsu, S.; Naito, S. Expression levels of drugmetabolizing enzyme, transporter, and nuclear receptor mRNAs in a novel three-dimensional culture system for human hepatocytes using micro-space plates. Drug Metab. Pharm. 2011, 26, 137-144. [CrossRef]

32. Ohtsuki, S.; Schaefer, O.; Kawakami, H.; Inoue, T.; Liehner, S.; Saito, A.; Ishiguro, N.; Kishimoto, W.; Ludwig-Schwellinger, E.; Ebner, T.; et al. Simultaneous absolute protein quantification of transporters, cytochromes P450, and UDP-glucuronosyltransferases as a novel approach for the characterization of individual human liver: Comparison with mRNA levels and activities. Drug Metab. Dispos. 2012, 40, 83-92. [CrossRef]

33. Soars, M.G.; Burchell, B.; Riley, R.J. In vitro analysis of human drug glucuronidation and prediction of in vivo metabolic clearance. J. Pharm. Exp. Ther. 2002, 301, 382-390. [CrossRef]

34. Drozdzik, M.; Busch, D.; Lapczuk, J.; Müller, J.; Ostrowski, M.; Kurzawski, M.; Oswald, S. Protein abundance of clinically relevant drug - metabolizing enzymes in the human liver and intestine: A comparative analysis in paired tissue specimens. Clin. Pharm. Ther. 2018, 104, 515-524. [CrossRef] [PubMed] 
35. Zhang, H.; Wolford, C.; Basit, A.; Li, A.P.; Fan, P.W.; Murray, B.P.; Takahashi, R.H.; Khojasteh, S.C.; Smith, B.J.; Thummel, K.; et al. Regional proteomic quantification of clinically relevant non-cytochrome P450 enzymes along the human small intestine. Drug Metab. Dispos. 2020, 48. [CrossRef]

36. Couto, N.; Al-Majdoub, Z.; Gibson, S.; Davies, P.; Achour, B.; Harwood, M.D.; Carlson, G.; Barber, J.; Rostami-Hodjegan, A.; Warhurst, G. Quantitative proteomics of clinically relevant drug-metabolizing enzymes and drug transporters and their inter-correlations in the human small intestine. Drug Metab. Dispos. 2020, 48. [CrossRef] [PubMed]

37. Akazawa, T.; Uchida, Y.; Miyauchi, E.; Tachikawa, M.; Ohtsuki, S.; Terasaki, T. High expression of UGT1A1/1A6 in monkey small intestine: Comparison of protein expression levels of Cytochromes P450, UDP-glucuronosyltransferases, and transporters in small Intestine of cynomolgus monkey and human. Mol. Pharm. 2017, 15, 127-140. [CrossRef] [PubMed]

38. Miyauchi, E.; Tachikawa, M.; Declèves, X.; Uchida, Y.; Bouillot, J.-L.; Poitou, C.; Oppert, J.-M.; Mouly, S.; Bergmann, J.-F.; Terasaki, T.; et al. Quantitative atlas of cytochrome P450, UDP-glucuronosyltransferase, and transporter proteins in jejunum of morbidly obese subjects. Mol. Pharm. 2016, 13, 2631-2640. [CrossRef]

39. Kasteel, E.E.J.; Darney, K.; Kramer, N.I.; Dorne, J.L.C.M.; Lautz, L.S. Human variability in isoform-specific UDPglucuronosyltransferases: Markers of acute and chronic exposure, polymorphisms and uncertainty factors. Arch. Toxicol. 2020, 94, 2637-2661. [CrossRef]

40. Lv, X.; Zhang, J.B.; Hou, J.; Dou, T.Y.; Ge, G.B.; Hu, W.Z.; Yang, L. Chemical probes for human UDP-glucuronosyltransferases: A comprehensive review. Biotechnol. J. 2019, 14, e1800002. [CrossRef]

41. Wegler, C.; Gaugaz, F.Z.; Andersson, T.B.; Wiśniewski, J.R.; Busch, D.; Gröer, C.; Oswald, S.; Norén, A.; Weiss, F.; Hammer, H.S.; et al. Variability in mass spectrometry-based quantification of clinically relevant drug transporters and drug metabolizing enzymes. Mol. Pharm. 2017, 14, 3142-3151. [CrossRef] [PubMed]

42. Prasad, B.; Achour, B.; Artursson, P.; Hop, C.E.C.A.; Lai, Y.; Smith, P.C.; Barber, J.; Wisniewski, J.R.; Spellman, D.; Uchida, Y.; et al. Toward a consensus on applying quantitative liquid chromatography-tandem mass spectrometry proteomics in translational pharmacology research: A white paper. Clin. Pharm. Ther. 2019, 106, 525-543. [CrossRef]

43. Paine, M.F.; Khalighi, M.; Fisher, J.M.; Shen, D.D.; Kunze, K.L.; Marsh, C.L.; Thummel, J.D.P.; Kenneth, E.; Thummel, K.E. Characterization of interintestinal and intraintestinal variations in human CYP3A-dependent metabolism. J. Pharm. Exp. Ther. 1997, 283, 1552-1562.

44. Di, L.; Obach, R.S. Addressing the challenges of low clearance in drug research. AAPS J. 2015, 17, 352-357. [CrossRef] [PubMed]

45. Kratochwil, N.A.; Meille, C.; Fowler, S.; Klammers, F.; Ekiciler, A.; Molitor, B.; Simon, S.; Walter, I.; McGinnis, C.; Walther, J.; et al. Metabolic profiling of human long-term liver models and hepatic clearance predictions from in vitro data using nonlinear mixed-effects modeling. AAPS J. 2017, 19, 534-550. [CrossRef]

46. Pelkonen, O.; Turpeinen, M. In vitro-in vivo extrapolation of hepatic clearance: Biological tools, scaling factors, model assumptions and correct concentrations. Xenobiotica 2007, 37, 1066-1089. [CrossRef] [PubMed]

47. Manevski, N.; Troberg, J.; Svaluto-Moreolo, P.; Dziedzic, K.; Yli-Kauhaluoma, J.; Finel, M. Albumin stimulates the activity of the human UDP-glucuronosyltransferases 1A7, 1A8, 1A10, 2A1 and 2B15, but the effects are enzyme and substrate dependent. PLoS ONE 2013, 8, e54767. [CrossRef]

48. Rowland, A.; Knights, K.M.; Mackenzie, P.I.; Miners, J.O. The "albumin effect" and drug glucuronidation: Bovine serum albumin and fatty acid-free human serum albumin enhance the glucuronidation of UDP-glucuronosyltransferase (UGT) 1A9 substrates but not UGT1A1 and UGT1A6 activities. Drug Metab. Dispos. 2008, 36, 1056-1062. [CrossRef]

49. Walsky, R.L.; Bauman, J.N.; Bourcier, K.; Giddens, G.; Lapham, K.; Negahban, A.; Ryder, T.F.; Obach, R.S.; Hyland, R.; Goosen, T.C. Optimized assays for human UDP-glucuronosyltransferase (UGT) activities: Altered alamethicin concentration and utility to screen for UGT inhibitors. Drug Metab. Dispos. 2012, 40, 1051-1065. [CrossRef]

50. Badée, J.; Qiu, N.; Parrott, N.; Collier, A.C.; Schmidt, S.; Fowler, S. Optimization of experimental conditions of automated glucuronidation assays in human liver microsomes using a cocktail approach and ultra-high performance liquid chromatographytandem mass spectrometry. Drug Metab. Dispos. 2019, 47, 124-134. [CrossRef]

51. Wood, F.L.; Houston, J.B.; Hallifax, D. Clearance prediction methodology needs fundamental improvement: Trends common to rat and human hepatocytes/microsomes and implications for experimental methodology. Drug Metab. Dispos. 2017, 45, 1178-1188. [CrossRef] [PubMed]

52. Bonn, B.; Svanberg, P.; Janefeldt, A.; Hultman, I.; Grime, K. Determination of human hepatocyte intrinsic clearance for slowly metabolized compounds: Comparison of a primary hepatocyte/stromal cell co-culture with plated primary hepatocytes and HepaRG. Drug Metab. Dispos. 2016, 44, 527-533. [CrossRef]

53. Chan, T.S.; Yu, H.; Moore, A.; Khetani, S.R.; Tweedie, D. Meeting the challenge of predicting hepatic clearance of compounds slowly metabolized by cytochrome P450 using a novel hepatocyte model, HepatoPac. Drug Metab. Dispos. 2019, 47, 58-66. [CrossRef]

54. Chen, Y.; Liu, L.; Nguyen, K.; Fretland, A.J. Utility of intersystem extrapolation factors in early reaction phenotyping and the quantitative extrapolation of human liver microsomal intrinsic clearance using recombinant cytochromes P450. Drug Metab. Dispos. 2011, 39, 373-382. [CrossRef]

55. Proctor, N.J.; Tucker, G.T.; Rostami-Hodjegan, A. Predicting drug clearance from recombinantly expressed CYPs: Intersystem extrapolation factors. Xenobiotica 2004, 34, 151-178. [CrossRef] [PubMed] 
56. Venkatakrishnan, K.; von Moltke, L.L.; Court, M.H.; Harmatz, J.S.; Crespi, C.L.; Greenblatt, D.J. Comparison between cytochrome P450 (CYP) content and relative activity approaches to scaling from cDNA-expressed CYPs to human liver microsomes: Ratios of accessory proteins as sources of discrepancies between the approaches. Drug Metab. Dispos. 2000, 28, 1493-1504.

57. Busse, D.; Leandersson, S.; Amberntsson, S.; Darnell, M.; Hilgendorf, C. Industrial approach to determine the relative contribution of seven major UGT isoforms to hepatic glucuronidation. J. Pharm. Sci. 2020, 109, 2309-2320. [CrossRef] [PubMed]

58. Peters, S.A.; Jones, C.R.; Ungell, A.L.; Hatley, O.J. Predicting drug extraction in the human gut wall: Assessing contributions from drug metabolizing enzymes and transporter proteins using preclinical models. Clin. Pharm. 2016, 55, 673-696. [CrossRef] [PubMed]

59. Ho, M.D.; Ring, N.; Amaral, K.; Doshi, U.; Li, A.P. Human enterocytes as an in vitro model for the evaluation of intestinal drug metabolism: Characterization of drug-metabolizing enzyme activities of cryopreserved human enterocytes from twenty-four donors. Drug Metab. Dispos. 2017, 45, 686-691. [CrossRef] [PubMed]

60. Li, A.P.; Alam, N.; Amaral, K.; Ho, M.D.; Loretz, C.; Mitchell, W.; Yang, Q. Cryopreserved human intestinal mucosal epithelium: A novel in vitro experimental system for the evaluation of enteric drug metabolism, cytochrome P450 induction, and enterotoxicity. Drug Metab. Dispos. 2018, 46, 1562-1571. [CrossRef] [PubMed]

61. Li, A.P.; Ho, M.D.; Alam, N.; Mitchell, W.; Wong, S.; Yan, Z.; Kenny, J.R.; Hop, C.E.C.A. Inter-individual and inter-regional variations in enteric drug metabolizing enzyme activities: Results with cryopreserved human intestinal mucosal epithelia (CHIM) from the small intestines of 14 donors. Pharmacol. Res. Perspect. 2020, 8, e00645. [CrossRef]

62. Khetani, S.R.; Bhatia, S.N. Microscale culture of human liver cells for drug development. Nat. Biotechnol. 2008, 26, 120-126. [CrossRef]

63. Reese, M.J.; Savina, P.M.; Generaux, G.T.; Tracey, H.; Humphreys, J.E.; Kanaoka, E.; Webster, L.O.; Harmon, K.A.; Clarke, J.D.; Polli, J.W. In vitro investigations into the roles of drug transporters and metabolizing enzymes in the disposition and drug interactions of dolutegravir, a HIV integrase inhibitor. Drug Metab. Dispos. 2013, 41, 353-361. [CrossRef] [PubMed]

64. Bowers, G.D.; Culp, A.; Reese, M.J.; Tabolt, G.; Moss, L.; Piscitelli, S.; Huynh, P.; Wagner, D.; Ford, S.L.; Gould, E.P.; et al. Disposition and metabolism of cabotegravir: A comparison of biotransformation and excretion between different species and routes of administration in humans. Xenobiotica 2015, 46, 147-162. [CrossRef] [PubMed]

65. Ford, S.L.; Sutton, K.; Lou, Y.; Zhang, Z.; Tenorio, A.; Trezza, C.; Patel, P.; Spreen, W. Effect of rifampin on the single-dose pharmacokinetics of oral cabotegravir in healthy subjects. Antimicrob. Agents Chemother. 2017, 61, e00487-17. [CrossRef]

66. Cottrell, M.L.; Hadzic, T.; Kashuba, A.D.M. Clinical pharmacokinetic, pharmacodynamic and drug-interaction profile of the integrase inhibitor dolutegravir. Clin. Pharm. 2013, 52, 981-994. [CrossRef]

67. Min, S.; Song, I.; Borland, J.; Chen, S.; Lou, Y.; Fujiwara, T.; Piscitelli, S.C. Pharmacokinetics and safety of S/GSK1349572, a next-generation HIV integrase inhibitor, in healthy volunteers. Antimicrob. Agents Chemother. 2010, 54, 254-258. [CrossRef] [PubMed]

68. Song, I.; Borland, J.; Chen, S.; Patel, P.; Wajima, T.; Peppercorn, A.; Piscitelli, S.C. Effect of Food on the Pharmacokinetics of the Integrase Inhibitor Dolutegravir. Antimicrob. Agents Chemother. 2012, 56, 1627-1629. [CrossRef] [PubMed]

69. Song, I.; Borland, J.; Chen, S.; Lou, Y.; Peppercorn, A.; Wajima, T.; Min, S.; Piscitelli, S.C. Effect of atazanavir and atazanavir/ritonavir on the pharmacokinetics of the next-generation HIV integrase inhibitor, S/GSK1349572. Brit. J. Clin. Pharm. 2011, 72, 103-108. [CrossRef] [PubMed]

70. Adams, J.L.; Patterson, K.B.; Prince, H.M.A.; Sykes, C.; Greener, B.N.; Dumond, J.B.; Kashuba, A.D.M. Single and multiple dose pharmacokinetics of dolutegravir in the genital tract of HIV negative women. Antivir. Ther. 2013, 18, 1005-1013. [CrossRef] [PubMed]

71. Greener, B.N.; Patterson, K.B.; Prince, H.M.A.; Sykes, C.S.; Adams, J.L.; Dumond, J.B.; Shaheen, N.J.; Madanick, R.D.; Dellon, E.S.; Cohen, M.S.; et al. Dolutegravir pharmacokinetics in the genital tract and colorectum of HIV-negative men after single and multiple dosing. Jaids J. Acquir. Immune Defic. Syndr. 2013, 64, 39-44. [CrossRef] [PubMed]

72. Johnson, M.; Borland, J.; Chen, S.; Savina, P.; Wynne, B.; Piscitelli, S. Effects of boceprevir and telaprevir on the pharmacokinetics of dolutegravir. Brit. J. Clin. Pharm. 2014, 78, 1043-1049. [CrossRef]

73. Ross, L.L.; Song, I.H.; Arya, N.; Choukour, M.; Zong, J.; Huang, S.-P.; Eley, T.; Wynne, B.; Buchanan, A.M. No clinically significant pharmacokinetic interactions between dolutegravir and daclatasvir in healthy adult subjects. BMC Infect. Dis. 2016, 16, 347. [CrossRef]

74. Song, I.; Borland, J.; Arya, N.; Wynne, B.; Piscitelli, S. Pharmacokinetics of dolutegravir when administered with mineral supplements in healthy adult subjects. J. Clin. Pharm. 2015, 55, 490-496. [CrossRef]

75. Song, I.; Borland, J.; Chen, S.; Guta, P.; Lou, Y.; Wilfret, D.; Wajima, T.; Savina, P.; Peppercorn, A.; Castellino, S.; et al. Effects of enzyme inducers efavirenz and tipranavir/ritonavir on the pharmacokinetics of the HIV integrase inhibitor dolutegravir. Eur. J. Clin. Pharm. 2014, 70, 1173-1179. [CrossRef]

76. Song, I.; Borland, J.; Min, S.; Lou, Y.; Chen, S.; Patel, P.; Wajima, T.; Piscitelli, S.C. Effects of etravirine alone and with ritonavir-boosted protease inhibitors on the pharmacokinetics of dolutegravir. Antimicrob. Agents Chemother. 2011, 55, 3517-3521. [CrossRef] [PubMed]

77. Song, I.; Weller, S.; Patel, J.; Borland, J.; Wynne, B.; Choukour, M.; Jerva, F.; Piscitelli, S. Effect of carbamazepine on dolutegravir pharmacokinetics and dosing recommendation. Eur. J. Clin. Pharm. 2016, 72, 665-670. [CrossRef] [PubMed] 
78. Song, I.H.; Borland, J.; Chen, S.; Savina, P.; Peppercorn, A.F.; Piscitelli, S. Effect of prednisone on the pharmacokinetics of the integrase inhibitor dolutegravir. Antimicrob. Agents Chemother. 2013, 57, 4394-4397. [CrossRef] [PubMed]

79. Zhang, D.; Chando, T.J.; Everett, D.W.; Patten, C.J.; Dehal, S.S.; Humphreys, W.G. In vitro inhibition of UDP glucuronosyltransferases by atazanavir and other HIV protease inhibitors and the relationship of this property to in vivo bilirubin glucuronidation. Drug Metab. Dispos. 2005, 33, 1729-1739. [CrossRef]

80. De Bruyn, T.; Stieger, B.; Augustijns, P.F.; Annaert, P.P. Clearance prediction of HIV protease inhibitors in man: Role of hepatic uptake. J. Pharm. Sci. 2016, 105, 854-863. [CrossRef]

81. Perloff, E.S.; Duan, S.X.; Skolnik, P.R.; Greenblatt, D.J.; von Moltke, L.L. Atazanavir: Effects on P-glycoprotein transport and CYP3A metabolism in vitro. Drug Metab. Dispos. 2005, 33, 764-770. [CrossRef] [PubMed]

82. Nicolaï, J.; De Bruyn, T.; Thevelin, L.; Augustijns, P.; Annaert, P. Transport-metabolism interplay of atazanavir in rat hepatocytes. Drug Metab. Dispos. 2016, 44, 389-397. [CrossRef]

83. Isentress [Package Insert]; Merck Co., Inc.: Kenilworth, NJ, USA, 2015.

84. Kassahun, K.; McIntosh, I.; Cui, D.; Hreniuk, D.; Merschman, S.; Lasseter, K.; Azrolan, N.; Iwamoto, M.; Wagner, J.A.; Wenning, L.A. Metabolism and disposition in humans of raltegravir (MK-0518), an anti-AIDS drug targeting the human immunodeficiency virus 1 integrase enzyme. Drug Metab. Dispos. 2007, 35, 1657-1663. [CrossRef] [PubMed]

85. Zhu, L.; Butterton, J.; Persson, A.; Stonier, M.; Comisar, W.; Panebianco, D.; Breidinger, S.; Zhang, J.; Bertz, R. Pharmacokinetics and safety of twice-daily atazanavir $300 \mathrm{mg}$ and raltegravir $400 \mathrm{mg}$ in healthy individuals. Antivir. Ther. 2010, 15, 1107-1114. [CrossRef] [PubMed]

86. Iwamoto, M.; Wenning, L.A.; Mistry, G.C.; Petry, A.S.; Liou, S.Y.; Ghosh, K.; Breidinger, S.; Azrolan, N.; Gutierrez, M.J.; Bridson, W.E.; et al. Atazanavir modestly increases plasma levels of raltegravir in healthy subjects. Clin. Infect. Dis. 2008, 47, 137-140. [CrossRef] [PubMed]

87. Neely, M.; Decosterd, L.; Fayet, A.; Lee, J.S.; Margol, A.; Kanani, M.; di Iulio, J.; von Schoen-Angerer, T.; Jelliffe, R.; Calmy, A. Pharmacokinetics and pharmacogenomics of once-daily raltegravir and atazanavir in healthy volunteers. Antimicrob. Agents Chemother. 2010, 54, 4619-4625. [CrossRef]

88. Paine, M.F.; Shen, D.D.; Kunze, K.L.; Perkins, J.D.; Marsh, C.L.; McVicar, J.P.; Barr, D.M.; Gillies, B.S.; Thummel, K.E. First-pass metabolism of midazolam by the human intestine. Clin. Pharm. Ther. 1996, 60, 14-24. [CrossRef]

89. Kharasch, E.D.; Walker, A.; Hoffer, C.; Sheffels, P. Intravenous and oral alfentanil as in vivo probes for hepatic and firstpass cytochrome P450 3A activity: Noninvasive assessment by use of pupillary miosis. Clin. Pharm. Ther. 2004, 76, 452-466. [CrossRef] [PubMed]

90. Varma, M.V.S.; Obach, R.S.; Rotter, C.; Miller, H.R.; Chang, G.; Steyn, S.J.; El-Kattan, A.; Troutman, M.D. Physicochemical space for optimum oral bioavailability: Contribution of human intestinal absorption and first-pass elimination. J. Med. Chem. 2010, 53, 1098-1108. [CrossRef] [PubMed]

91. Kiang, T.K.; Ensom, M.H.; Chang, T.K. UDP-glucuronosyltransferases and clinical drug-drug interactions. Pharmacol. Ther. 2005, 106, 97-132. [CrossRef] [PubMed]

92. King, C.; Tang, W.; Ngui, J.; Tephly, T.; Braun, M. Characterization of rat and human UDP-glucuronosyltransferases responsible for the in vitro glucuronidation of diclofenac. Toxicol. Sci. 2001, 61, 49-53. [CrossRef]

93. Jones, C.R.; Hatley, O.J.D.; Ungell, A.-L.; Hilgendorf, C.; Peters, S.A.; Rostami-Hodjegan, A. Gut wall metabolism. Application of pre-clinical models for the prediction of human drug absorption and first-pass elimination. AAPS J. 2016, 18, 589-604. [CrossRef]

94. Devineni, D.; Murphy, J.; Wang, S.S.; Stieltjes, H.; Rothenberg, P.; Scheers, E.; Mamidi, R.N.V.S. Absolute oral bioavailability and pharmacokinetics of canagliflozin: A microdose study in healthy participants. Clin. Pharm. Drug Dev. 2015, 4, 295-304. [CrossRef]

95. Devineni, D.; Vaccaro, N.; Murphy, J.; Curtin, C.; Mamidi, R.N.V.S.; Weiner, S.; Wang, S.-S.; Ariyawansa, J.; Stieltjes, H.; Wajs, E.; et al. Effects of rifampin, cyclosporine A, and probenecid on the pharmacokinetic profile of canagliflozin, a sodium glucose co-transporter 2 inhibitor, in healthy participants. Int. J. Clin. Pharm. Ther. 2015, 53, 115-128. [CrossRef]

96. Wenning, L.A.; Hanley, W.D.; Brainard, D.M.; Petry, A.S.; Ghosh, K.; Jin, B.; Mangin, E.; Marbury, T.C.; Berg, J.K.; Chodakewitz, J.A.; et al. Effect of rifampin, a potent inducer of drug-metabolizing enzymes, on the pharmacokinetics of raltegravir. Antimicrob. Agents Chemother. 2009, 53, 2852-2856. [CrossRef] [PubMed]

97. Boulton, D.W.; Kasichayanula, S.; Keung, C.F.; Arnold, M.E.; Christopher, L.J.; Xu, X.; LaCreta, F. Simultaneous oral therapeutic and intravenous 14C-microdoses to determine the absolute oral bioavailability of saxagliptin and dapagliflozin. Brit. J. Clin. Pharm. 2013, 75, 763-768. [CrossRef]

98. Raje, S.; Callegari, E.; Sahasrabudhe, V.; Vaz, A.; Shi, H.; Fluhler, E.; Woolf, E.J.; Schildknegt, K.; Matschke, K.; Alvey, C.; et al. Novel application of the two-period microtracer approach to determine absolute oral bioavailability and fraction absorbed of ertugliflozin. Clin. Transl. Sci. 2018, 11, 405-411. [CrossRef]

99. Davies, B.; Morris, T. Physiological parameters in laboratory animals and humans. Pharm. Res. 1993, 10, 1093-1095. [CrossRef] [PubMed]

100. Cubitt, H.E.; Houston, J.B.; Galetin, A. Prediction of human drug clearance by multiple metabolic pathways: Integration of hepatic and intestinal microsomal and cytosolic data. Drug Metab. Dispos. 2011, 39, 864-873. [CrossRef] [PubMed]

101. Zhao, P.; Zhang, L.; Grillo, J.A.; Liu, Q.; Bullock, J.M.; Moon, Y.J.; Song, P.; Brar, S.S.; Madabushi, R.; Wu, T.C.; et al. Applications of physiologically based pharmacokinetic (PBPK) modeling and simulation during regulatory review. Clin. Pharm. Ther. 2011, 89, 259-267. [CrossRef] [PubMed] 
102. Lewinsky, R.H.; Smith, P.A.; Mackenzie, P.I. Glucuronidation of bioflavonoids by human UGT1A10: Structure-function relationships. Xenobiotica 2005, 35, 117-129. [CrossRef]

103. Sorich, M.J.; McKinnon, R.A.; Miners, J.O.; Smith, P.A. The importance of local chemical structure for chemical metabolism by human uridine 5'-diphosphate-glucuronosyltransferase. J. Chem. Inf. Modeling 2006, 46, 2692-2697. [CrossRef] 